\title{
An Enthusiastic Glance in to the Visible Responsive Photocatalysts for Energy Production and Pollutant Removal, with Special Emphasis on Titania
}

\author{
Padikkaparambil Silija, ${ }^{1}$ Zahira Yaakob, ${ }^{1}$ Viswanathan Suraja, ${ }^{1}$ \\ Njarakkattuvalappil Narayanan Binitha, ${ }^{2}$ and Zubair Shamsul Akmal ${ }^{1}$ \\ ${ }^{1}$ Department of Chemical and Process Engineering, Faculty of Engineering and Built Environment, Universiti Kebangsaan Malaysia, \\ Selangor 43600 Bangi, Malaysia \\ ${ }^{2}$ Department of Chemistry, Sree Neelakanta Government Sanskrit College, Pattambi, Kerala, Palakkad 679306, Malaysia
}

Correspondence should be addressed to Zahira Yaakob, zahira65@yahoo.com

Received 15 July 2011; Accepted 19 August 2011

Academic Editor: Jae Sung Lee

Copyright ( 2012 Padikkaparambil Silija et al. This is an open access article distributed under the Creative Commons Attribution License, which permits unrestricted use, distribution, and reproduction in any medium, provided the original work is properly cited.

\begin{abstract}
As a consequence of the rapid growth of industry, major problems are created related to energy and environment. Sunlight being one of the most potential alternative source of energy, the development of efficient solar-energy storage systems is an important subject in the fields of science and technology. Here we have reviewed and summarized some of the recent reports on visible responsive photocatalysts. In this review, the influence of various metal oxide photocatalysts on energy production and pollutant removal are presented with special emphasis on titania based photocatalysts. The photoactivity of titania for various pollutant degradation, modified titania $\left(\mathrm{TiO}_{2}\right)$ systems, their physical and chemical characteristics, and so forth, are described in detail at this juncture. Different methods used to enhance the visible light absorption of $\mathrm{TiO}_{2}$, like doping with metals and nonmetals, coupling with other metal oxides, and so forth, have been discussed. Various applications of photocatalysts including photocatalytic treatment of waste water, pesticide degradation and water splitting to produce hydrogen are summarized. The development of photocatalysts that function under visible light for the efficient utilization of sunlight is an area of current interest and thus the different methods of preparation for the visible active photocatalysts are also explored.
\end{abstract}

\section{Introduction}

Photochemistry deals with the chemical changes brought about by light. Its important aim is to discover or to design structurally organized and functionally integrated artificial systems that are capable of harvesting solar energy, to perform useful functions. Energy crisis is the main impetus to the study of photochemical reactions. The photochemical changes such as photofading of coloured materials, photosynthesis in plants, and blackening of silver halides, and were observed and so forth, studied qualitatively from 1817 onwards. The quantitative approach to photochemistry was initiated by Grotthus and Draper in the beginning of the nineteenth century, and it was formulated that only the light which is absorbed by a system can cause any chemical change. The probability or rate of absorption is given by the Lambert-Beer Law [1].

Photocatalysis is found to be an eco-friendly cheap method for removing various pollutants from gas and liquid streams and conversion of solar energy to chemical energy by splitting water $\left(\mathrm{H}_{2}\right.$ generation) and reducing $\mathrm{CO}_{2}$ into light hydrocarbons. Splitting of water is a process that has great potential for the conversion of photo energy to chemical energy, in the form of hydrogen [2]. Millions of tonnes of $\mathrm{H}_{2} \mathrm{~S}$ are produced in petroleum refinery plants in every year and is expected to increase considerably in the future $[3,4]$. Thus, among various methods of solar energy conversions, much attention has been paid to photocatalytic decomposition of $\mathrm{H}_{2} \mathrm{~S}$, for its potential in obtaining clean and high energy containing $\mathrm{H}_{2}$ from abundant $\mathrm{H}_{2} \mathrm{~S}$. As the 
direct thermal decomposition of $\mathrm{H}_{2} \mathrm{~S}$, for the production of hydrogen and elemental sulfur is energy intensive and economically unviable, there has been immense emphasis on the development of visible light photocatalysts for the production of hydrogen [5]. The development of a particulate photocatalyst that catalyzes overall water splitting under visible light for large-scale production of $\mathrm{H}_{2}$ from water and sunlight, has become an important endeavor [69]. It is also essential to find an alternative to fossil-fuelbased energy sources, for establishing new energy systems for the 21 st century. Thus, photocatalysis appeared as a "green" technology with promising applications in a wide assortment of chemical and environmental technologies.

Over the past decades, photocatalytic activity of semiconducting inorganic solids have attracted passionate research interest for the degradation of organic pollutants and/or the decomposition of water molecules $[10,11]$. Semiconductors (such as $\mathrm{TiO}_{2}, \mathrm{ZnO}, \mathrm{Fe}_{2} \mathrm{O}_{3}$, CdS, and $\mathrm{ZnS}$ ), which are characterized by a filled valence band and an empty conduction band [12], are proved to be important materials due to the electronic structure of the metal atoms in chemical combination.

The major organic compounds that constitute the industrial waste water include dyes, phenols, chlorophenols, aliphatic alcohols, aromatics, polymers, and carboxylic acids. Although, dyes are creating a colorful world, they are becoming a major source of environmental contamination, as their release into the ecosystem is a dramatic source of aesthetic pollution, eutrophication, and perturbation in aquatic systems [13]. Colour removal, especially from textile waste water, has been a big challenge over the last decades [14]. The conventional technologies are not capable of reducing them to the lowest levels demanded by the environmental laws. The complexity and variety of dyestuffs employed in the dying processes made it difficult to find a unique treatment procedure that entirely covers the effective elimination of all types of dyes. Principally, biochemical oxidations go through considerable restrictions in view of the fact that the majority of dyestuffs commercially available have been deliberately planned to resist aerobic microbial degradation and are thus, converted to toxic or carcinogenic compounds. Physical processes, for example, flocculation, reverse osmosis, and adsorption on activated charcoal are nondestructive and simply transfer the pollutant to another media, consequently causing secondary pollution. Among the advanced oxidation processes (AOP) prompted for treating both gas and water pollutants, the heterogeneous photocatalysis is a powerful tool to solve environmental and energy problems $[15,16]$. Injurious atmospheric pollutants, which are exhausted from internal combustion engines and furnaces, like nitrogen oxides $\left(\mathrm{NO}_{x}\right)$ such as nitric oxide $(\mathrm{NO})$, nitrous oxide $\left(\mathrm{N}_{2} \mathrm{O}\right)$, and nitrogen dioxide $\left(\mathrm{NO}_{2}\right)$ originates acid rain, photochemical smog, and greenhouse effects. Therefore, successful removal of the above pollutants has become a vital topic in the meadow of environmental protection, and there had appeared many winning reports on the catalytic oxidation of $\mathrm{NO}_{x}$ under photo irradiation.

Photocatalytic treatment plays an important role in the environmental and energy applications, including purifi- cation and recycling of waste water and degradation of pesticides, dyes, and other volatile organic compounds. Production of hydrogen by water splitting becoming an interesting area of research. For the efficient utilization of solar energy, photocatalysts exhibiting longer wavelength absorption are highly desirable. In the present review, we have tried to make an illumination into the visible responsive photocatalytic world.

\section{Effect of Band Gap}

Generally, photodissociation driven by a semiconductor originates from a redox reaction with transient electrons or holes generated by an electronic transition from valence band $(\mathrm{VB})$ to conduction band $(\mathrm{CB})$, by the absorption of light with energy equal to or greater than the band gap of the semiconductor. The separated photo-induced electrons and holes transferred themselves efficiently to the semiconductor surface. At the surface, electrons react with acceptors (usually $\mathrm{O}_{2}$ dissolved in the solution) to produce radical anions such as $\mathrm{O}_{2}^{-}$. Meanwhile, holes react with donors $\left(\mathrm{H}_{2} \mathrm{O}\right.$, $\mathrm{OH}^{-}$) to produce oxidant species such as $\mathrm{OH}^{\cdot}$. These highly active species, which are produced from electrons and holes, have strong oxidizing and reducing abilities and can directly oxidize organic compounds into $\mathrm{CO}_{2}$ and $\mathrm{H}_{2} \mathrm{O}$. So the efficiency of photocatalysts strongly depends on their band structures such as bandgap energy $\left(E_{g}\right)$ and the positions of $\mathrm{VB}$ and $\mathrm{CB}$.

Due to the large band gap, these semiconductors could be activated only by UV irradiation. This limited the utilization of sunlight as an irradiation source in photocatalytic reactions. It is known that the UV part of the solar spectrum accounts only for about $5 \%$ of the incoming solar energy while the rest is visible light. The holes and electrons excited by the UV light can recombine easily, which will reduce the efficiency of photons. Thus suppression of the recombination of hole-electron pairs is a necessity. Therefore, a photocatalyst material having visible light activity is required for harvesting solar energy and interior lighting applications. It is therefore of great significance to adjust the band structure of photocatalyst to improve photocatalysis by efficient utilisation of solar energy. There have been many attempts such as dye sensitization, coupling of different semiconductors, and so forth are performed to optimize the band structure of semiconducting photocatalysts $[17,18]$. Recently, attempts have been made to modify the band gap energy simply by substituting metal or oxygen ions in part of the oxide lattice [19-21].

\section{Visible Light Responsive Photocatalysts}

Semiconductor photocatalysts had been widely employed in pollutant removal as well as energy production, after the early work on $\mathrm{TiO}_{2}$ photoelectrochemical hydrogen production reported by Fujishima and Honda [10]. Nowadays scientific and engineering interests in semiconductor photocatalysis have full grown extensively. The major limitations of the application of semiconductor photocatalysts, 
as mentioned before, are their high band gap and UV light activity. Smoothening of the progress of their applications necessitated the use of sunlight or visible light responsive systems, which can make the process of semiconductor photocatalysis economical. In the preceding sections different photocatalysts and the factors leading to their visible light response are sighted (see Figure 1).

3.1. Titania. $\mathrm{TiO}_{2}$ is one of the most talented heterogeneous photocatalysts because of its first-rate properties such as high photocatalytic activity, strong oxidizing power, low cost, chemical and thermal stability, resistance to photo corrosion and nontoxicity, in addition to its favorable optoelectronic property [22]. $\mathrm{TiO}_{2}$ is also a very popular material for optical and protective applications, because of its high transparency in the visible region [23] and excellent mechanical durability. Anatase, rutile, and brookite are the three phases in which $\mathrm{TiO}_{2}$ usually exists in nature. Among them anatase and rutile are commonly utilized as photocatalysts. Even though anatase is believed to be the more reactive phase of $\mathrm{TiO}_{2}$ than rutile crystalline phase, it has low quantum yield for oxidation steps $(\sim 5 \%)$ as a result of rapid recombination of photogenerated electron-hole pairs [24]. The high intrinsic band gap energy of pure $\mathrm{TiO}_{2}$ photocatalysts $(3.2 \mathrm{eV}$ for anatase phase and $3.0 \mathrm{eV}$ for rutile) made anatase operate effectively as a photocatalyst only when the wavelengths of light are shorter than $387 \mathrm{~nm}$. Thus, pure anatase is able to use only around $4 \%$ of the terrestrial solar spectrum because of its wide band gap [25]. Many attempts have been made to make it active in the visible range, which include dye sensitization, metal ion doping, nonmetal doping, and so forth [19-21].

The rutile phase of $\mathrm{TiO}_{2}$ has a slightly smaller band gap $(3.0 \mathrm{eV})$, and, therefore, rutile should be photoexcited more easily [26]. The higher recombination rate of photo-generated charge carriers is the major reason for the poor photocatalytic activity of rutile as compared to anatase [19]. The most feasible methods for humanizing the photocatalytic performance of $\mathrm{TiO}_{2}$ are doping with metals and nonmetals. Doped metal atoms could suppress the recombination of photo-induced electron-hole pairs, where the excited electron migrates from the inside of the photocatalyst to the surface of the metal so as to increase the photo quantum efficiency $[19,27]$ by trapping the electron from recombination. On the other hand, nonmetal doping decreases the band gap, and shifts the response to the visible part of the solar spectrum by incorporating nonmetal atoms into the lattice structure of $\mathrm{TiO}_{2}[21,28,29]$. Based on literature review, the outcome of different attempts to improve the photoactivity of $\mathrm{TiO}_{2}$ is described in the following sections.

3.1.1. Metal-Doped Visible Light Active $\mathrm{TiO}_{2}$. The second most detrimental aspects of the photoactivity of $\mathrm{TiO}_{2}$ is its relatively high electron-hole recombination rate. Previous studies demonstrated that the appropriate amount of metals doped on $\mathrm{TiO}_{2}$ could inhibit the recombination of photo-induced electron-hole pairs $[30,31]$. The change

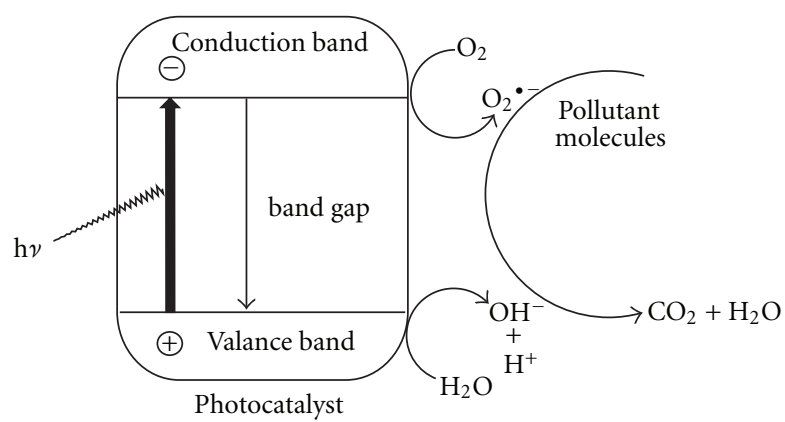

FIgURE 1: Pictorial representation of semiconductor photocatalyst band structure that leads to pollutant degradation upon exposure to light.

in electronic properties of $\mathrm{TiO}_{2}$ by substitution of metal ion for $\mathrm{Ti}^{4+}$ sufficiently reduced the energy band gap to absorb visible light. Abundant studies were reported for the characteristic behavior of visible-active metal-doped semiconductor photocatalysts where the dopants include noble metals [32], rare earth metals [31], and transition metals, and so forth [33]. Silver and gold nanoparticles possess additional ability to absorb visible light, due to localized surface plasmon resonance (LSPR) [34], which again contributes to the visible light activity, when the noble metals are doped over $\mathrm{TiO}_{2}$.

A series of transition metal ions, such as $\mathrm{Cr}, \mathrm{Mn}$, and Co, when doped in $\mathrm{TiO}_{2}$ powders by hydrolysis method [35] and showed considerable shift of absorption towards visible light region. $\mathrm{Li}$ and $\mathrm{Li}$ reported $\mathrm{Au}^{3+}$ doped $\mathrm{TiO}_{2}$ for the photodegradation of methylene blue (MB) under visible light [36]. Kim et al. reported the preparation of Pt iondoped $\mathrm{TiO}_{2}$ for the photodegradation of chlorinated organic compounds under visible light irradiation [37]. The photoactivity of $\mathrm{TiO}_{2}$ could be enhanced by the incorporation of lanthanide ions into $\mathrm{TiO}_{2}$ matrix. Lanthanide ions have the aptitude to form complexes with a variety of Lewis bases (including organic acids, amines, aldehydes, alcohols, and thiols) by the interaction of functional groups with f-orbitals of lanthanides. This could provide a way to concentrate organic pollutant at the semiconductor surface [38]. Thus, $\mathrm{TiO}_{2}$, doped with lanthanide metals, such as $\mathrm{La}^{3+}, \mathrm{Eu}^{3+}$, $\mathrm{Nd}^{3+}$, and $\mathrm{Ce}^{4+}$, produces effective photocatalysts that are found to be visible-light active [39-42]. The vanadium ions showed a marked effect in the red shift of the spectral response of $\mathrm{TiO}_{2}$ [43]. Vanadium dopant is accounted as one of the best metal dopants to extend the optical absorption of $\mathrm{TiO}_{2}$ towards the visible light region [44]. The enhanced absorption to visible light region and improved quantum efficiency, owing to the improvement in $\mathrm{e}^{-}-\mathrm{h}^{+}$pair separation make $\mathrm{TiO}_{2}$ an efficient photocatalyst in the presence of vanadium. The $\mathrm{V}^{4+}$ species in the $\mathrm{V}$-doped $\mathrm{TiO}_{2}$ materials could act as a trapping center for both $\mathrm{h}^{+}$and $\mathrm{e}^{-}$, favoring charge separation, while $\mathrm{V}^{5+}$ might have acted as an electron acceptor [45-47]. Xu et al. [48] reported that, the presence of Gd in $\mathrm{TiO}_{2}$ accelerated interfacial electron transfer process and thus exhibited better photocatalytic activity. Though DRS results showed more red-shift on higher Gd-doping, 
the photoactivity was not consistent with the result. It may be due to the large amount of Gd which would form recombination centers where photo-induced carriers could be captured, which led to a lower photocatalytic activity. Fe doping is also found to be highly efficient to impart visible activity to $\mathrm{TiO}_{2}$. $\mathrm{Fe}_{2} \mathrm{O}_{3}$-modified $\mathrm{TiO}_{2}$ nanotube arrays were first prepared by Kuang et al. [49] by annealing anodic $\mathrm{TiO}_{2}$ nanotubes preloaded with $\mathrm{Fe}(\mathrm{OH})_{3}$ which was uniformly clung to the $\mathrm{TiO}_{2}$ nanotubes using sequential chemical bath deposition ( $\mathrm{S}-\mathrm{CBD}$ ). $\mathrm{Fe}_{2} \mathrm{O}_{3}$-modified systems showed higher photopotential and photocurrent values than those of unmodified $\mathrm{TiO}_{2}$ nanotubes. The maximum photocurrent was obtained with 0.5 at $\% \mathrm{Fe}$ content, which was 7 times greater than that achieved with unmodified $\mathrm{TiO}_{2}$ nanotubes. The enhanced photoelectrochemical behaviours can be attributed to the shifting of photoresponse of $\mathrm{TiO}_{2}$ from UV to visible region due to the low band gap of $2.2 \mathrm{eV}$ of $\mathrm{Fe}_{2} \mathrm{O}_{3}$. The $\mathrm{Fe}_{2} \mathrm{O}_{3}$-modified samples also resulted in a negative shift of the zero-current potential from -0.36 to $-0.78 \mathrm{~V}$, which further confirmed that the enhancement in the separation of the photogenerated $\mathrm{e}^{-}-\mathrm{h}^{+}[50]$.

3.1.2. Nonmetal Doping on $\mathrm{TiO}_{2}$. Considerable efforts have been made to extend the photoactivity of $\mathrm{TiO}_{2}$-based systems into the visible light region for the efficient utilization of solar energy. Nonmetal doping is an alternative for improving the visible light response of $\mathrm{TiO}_{2}$, and extensive research work has been done on synthesis of N-doped, S-doped, F-doped, and $\mathrm{C}$ doped $\mathrm{TiO}_{2}$ [51-54]. The doping with nonmetal could narrow down the band gap by modifying the electronic structure around the conduction band edge of $\mathrm{TiO}_{2}$, by incorporating anion into the crystal lattice of $\mathrm{TiO}_{2}$ [21]. This might drive better photocatalytic performance under visible light [21, 28]. Recently, many researchers paid much attention to nitrogen-doped $\mathrm{TiO}_{2}$, which can be produced using different techniques, such as hydrolytic process $[55,56]$, mechanochemical technique $[57,58]$, and reactive DC magnetron sputtering, and so forth $[59,60]$. The first study on nitrogen-doped $\mathrm{TiO}_{2}$ including its visible light photocatalysis was conducted by Sato in 1986 [61]. The mixtures of a commercial titanium hydroxide and ammonium chloride calcined at about $400^{\circ} \mathrm{C}$ showed higher photocatalytic activity in the visible lightregion due to the presence of nitrogen and, thereafter $\mathrm{N}$-doping is considered as an efficient method to extend the optical absorption edge of $\mathrm{TiO}_{2}$ into the visible light region $[21,59,61]$. Similarly, carbon and sulphur were identified to form new impurity levels closest to the valence band whilst maintaining the largest band gap for maximum efficiency. Carbondoped $\mathrm{TiO}_{2}$ obtained by controlled combustion of Ti metal showed an impressive performance for photochemical water splitting under visible light [28]. Khan et al. [28] reported a chemically modified C-doped $\mathrm{TiO}_{2}$ as the photochemical water splitting material under visible light. Chou et al. reported carbon containing nanostructured mixed $\mathrm{TiO}_{2}$ phases with enhanced visible light photoactivity [62]. Wong et al. [63] fabricated carbon-incorporated $\mathrm{TiO}_{2}$ films in an anatase structure. The carbon was present both in the form of substituted Ti-C bonds and free graphitic carbon. The films exhibited absorption bands in the visible light region, with an absorption edge red-shifted up to $\sim 450 \mathrm{~nm}$, corresponding to a band gap $\sim 2.7 \mathrm{eV}$, with the gradual increment of carbon content. The films possessed outstanding visible light-induced photocatalytic properties in the reduction of silver ions, degradation of $\mathrm{MB}$, and super-hydrophilicity. Park et al. demonstrated the catalytic efficiency of the Cdoped $\mathrm{TiO}_{2}$ nanotubes, for water splitting under visible light irradiation, which was prepared at an elevated temperature range of $500-800^{\circ} \mathrm{C}$, by using carbon monoxide precursor [64]. Visible light responsive, carbon doped $\mathrm{TiO}_{2}$ films were developed by ion-assisted electron-beam evaporation using rutile powder as source material and two different gases, $\mathrm{CO}_{2}$ and $\mathrm{CO}$, in the ion source as dopant source by Wong et al. [65]. The annealed, carbon-doped, anatase $\mathrm{TiO}_{2}$ film, with a carbon content of $1.25 \mathrm{wt} \%$, gave the best visible light photocatalytic activity for super hydrophilicity, degradation of $(\mathrm{MB})$, and reduction of silver ions.

Asahi et al. [21] and other investigators [58, 66] reported the shifting of optical absorption edge to the visible region because of the narrowing of the band gap, by mixing the $\mathrm{N} 2 \mathrm{p}$ and $\mathrm{O} 2 \mathrm{p}$ states in $\mathrm{N}$-doped $\mathrm{TiO}_{2}$. It has initiated a new research area to extend the photo absorbance into the visible light region using nitrogen-doped $\mathrm{TiO}_{2}$. But most of current researchers supported an alternative proposal in which the dopant atom orbitals generate an isolated mid-gap level above the valence band $[51,56,67]$. Irie et al. suggested that the formation of an isolated N 2p narrow band above the $\mathrm{O} 2 \mathrm{p}$ valence band is responsible for the visible light response in the nitrogen-doped $\mathrm{TiO}_{2}$ [51]. Doped nitrogen can be incorporated into the $\mathrm{TiO}_{2}$ structure as substituted $\mathrm{N}$ and/or as interstitial N. Peng et al. [68] found that the interstitial N impurities can enhance the photoactivity of $\mathrm{TiO}_{2}$ in visible light and the activity was found to be higher than that of substitutional $\mathrm{N}$-doped $\mathrm{TiO}_{2}$. But, some researches $[69,70]$ presented that the interstitial $\mathrm{N}$ impurities might reduce the direct oxidation ability of sample in the photocatalytic process by acting as stronger hole trapping sites.

Burda et al. [71] used triethylamine as the $\mathrm{N}$-dopant to get nitrogen-doped $\mathrm{TiO}_{2}$, with an average grain size of 6$10 \mathrm{~nm}$, which could absorb well in the visible light region up to $600 \mathrm{~nm}$. Based on theoretical predictions and available experimental results, recently Wang and Lewis [72] had reported that carbon doping of $\mathrm{TiO}_{2}$ gave the best photoresponse compared to nitrogen or sulfur doping. A series of nitrogen-doped $\mathrm{TiO}_{2}$ catalysts were generated by Qin et al. [73] with N/Ti proportioning of $4,8,12,20,24,28$, and $32 \mathrm{~mol} \%$. Among them N/Ti $=20 \mathrm{~mol} \%$ showed highest catalytic activity and, they stated that an optimal content of $\mathrm{Ti}^{3+}$ might be the critical factor leading to the improvement of the photoactivity. This observation is supported by the previous report, which affirmed that in nitrogen-doped $\mathrm{TiO}_{2}$ catalysts, the oxygen sites were partially replaced with nitrogen atoms, while $\mathrm{TiO}_{2}$ was simultaneously reduced [74] and it leads to an increase in oxygen vacancy and amount of $\mathrm{Ti}^{3+}$. As the concentration of dopant increased, more $\mathrm{TiO}_{2}$ was reduced and the amount of oxygen vacancies increased. When it is excessively high, the space charge region became very narrow and the penetration depth of 
light into $\mathrm{TiO}_{2}$ greatly exceeded the space charge layer and thus the recombination of photo-generated electron hole pairs became easier [39]. Here, excessive oxygen vacancy and $\mathrm{Ti}^{3+}$ acted as a recombination center for holes and electrons [51]. N-doped $\mathrm{TiO}_{2}$ is mainly applied for the removal of various types of organic pollutants from the environment such as acetaldehyde [75], methylcyclohexene [76], benzoic acid [77], and dyes [78]. Wang et al. [79] demonstrated a unique incorporation of carbon into $\mathrm{TiO}_{2}$ films with carbon-covered (along grain boundaries) columnar grains of carbon-doped (inside the grains) anatase phase, using the method of reactive magnetron sputtering. The characterizations revealed that carbon is incorporated both in the form of substituted $\mathrm{Ti}-\mathrm{C}$ bonds as well as free graphitic nature. The gradual increment of power of the graphite target shifted the absorption edge of the $\mathrm{TiO}_{2-x} \mathrm{C}_{x}$ :C films from ultraviolet to visible region which increased the photocatalytic performance with retained crystallinity, even at a high carbon content of $9.3 \%$.

3.1.3. Effect of Codoping on $\mathrm{TiO}_{2}$. The modification of $\mathrm{TiO}_{2}$ by codoping is an effective method apart from doping $\mathrm{TiO}_{2}$ with a single metal or nonmetal. It is highly anticipated that doping $\mathrm{TiO}_{2}$ with an appropriate combination of metals and/or nonmetals would, of course, result in more visible light-sensitive photocatalysts for a desired application. Many of the recent efforts and strategies revealed that codoping of $\mathrm{TiO}_{2}$ with a metal and a nonmetal can result in the development of highly efficient visible active photocatalysts [80-82]. Zhao et al. [82] reported an improvement in both spectral response and photocatalytic efficiency through a combined action of a nonmetal and a metal oxide. They had prepared $\mathrm{Ni}_{2} \mathrm{O}_{3} / \mathrm{TiO}_{2-x} \mathrm{~B}_{x}$ photocatalyst by a simple modified sol-gel method. They demonstrated that incorporation of $\mathrm{B}$ into $\mathrm{TiO}_{2}$ could extend the spectral response to the visible region, and the photocatalytic activity was greatly enhanced when $\mathrm{Ni}_{2} \mathrm{O}_{3}$ was further loaded into it. Sakatani et al. [81] reported that $\mathrm{La}-\mathrm{N}-\mathrm{TiO}_{2}$ photocatalyst prepared by means of a Polymerization method which could effectively decompose acetaldehyde under visible light irradiation. Shi et al. [83] reported the cooperative effects of the two dopants $\mathrm{Fe}^{3+}$ and $\mathrm{Ho}^{3+}$ ions that resulted in improved photocatalytic activity to the codoped $\mathrm{TiO}_{2}$. $\mathrm{Li}$ et al. [84] pointed out high photocatalytic activity for $\mathrm{N}-$ F codoped catalyst prepared by pyrolysis method, and the high visible light activity was ascribed to a synergetic effect of its unique surface characteristics, doped $\mathrm{N}$ atoms, and doped $\mathrm{F}$ atoms. Yuan et al. [85] revealed the cooperative action of $\mathrm{Zn}^{2+}$ and $\mathrm{Fe}^{3+}$, over $\mathrm{TiO}_{2}$, in the photocatalytic degradation of phenol. The mechanisms of modification using metal and nonmetal element are completely different. Metal atoms either form individual phases dispersed into $\mathrm{TiO}_{2}$ or accommodate into the lattices of $\mathrm{TiO}_{2}$, which are primarily related to metal ion radii [86] while nonmetal atoms can enter into $\mathrm{TiO}_{2}$ lattice $[21,28]$. So it is expected that the doping with different transition metals, rare earth metals, nonmetals as well as their combination can be used to raise the photoactivity of $\mathrm{TiO}_{2}$ synergistically. Balek et al. [87] reported that the nitrogen and fluorine codoped
$\mathrm{TiO}_{2}$ photocatalyst prepared by spray pyrolysis using a mixed solution of $\mathrm{TiCl}_{4}$ and $\mathrm{NH}_{4} \mathrm{~F}$ showed high photocatalytic activity in the visible region of spectrum for acetaldehyde decomposition. They demonstrated that the observed high photocatalytic activity of the samples could be ascribed to a synergetic effect due to the codoping of nitrogen and fluorine. Ling et al. [88] prepared the $\mathrm{B}$ and $\mathrm{N}$ codoped $\mathrm{TiO}_{2}$ nanopowders using boric acid and ammonium fluoride as the precursors of boron and nitrogen and proved the synergistic effect of $\mathrm{B} / \mathrm{N}$ codoping, in its photocatalytic performance. Ling et al. [88] prepared $\mathrm{B} / \mathrm{Fe} / \mathrm{Ce}$ codoped $\mathrm{TiO}_{2}$, and their characterization results showed that $\mathrm{B}$ doping led to the modification of electronic structure around the conduction band edge of $\mathrm{TiO}_{2}$, and eventually resulted in the visible light response. In fact, the $\mathrm{Ti} 3 \mathrm{~d}$ orbital of $\mathrm{TiO}_{2}$ split into two parts, and the $\mathrm{CB}$ was divided into the lower and upper parts. On doping $\mathrm{TiO}_{2}$ with $\mathrm{B}$, the $\mathrm{B} 2 \mathrm{p}$ states are somewhat delocalized and thus resulted in the modification of the electronic structure around the conduction band edge of $\mathrm{TiO}_{2}$. The mixing of the $\mathrm{B} 2 \mathrm{p}$ states with $\mathrm{VB}$ increased the width of the $\mathrm{VB}$ itself and thus decreases the band gap energy [89]. By investigating the electronic and optical properties of several possible B-doped models, Yang et al. [90] pointed out that the transition of excited electrons from the valence band to the empty gap states above the Fermi level might be responsible for the red shift of the absorption edge in substitutional B- to O-doped anatase. Zhao et al. [82] had preformed theoretical calculations and found that the mixing of $\mathrm{p}$ orbital of $\mathrm{B}$ with $\mathrm{O} 2 \mathrm{p}$ orbital was responsible for narrowing of the band gap by calculating the densities of states (DOSs). According to the reports $[31,85]$ on degrading dichlorophenol, $\mathrm{Fe}^{3+}$ ion trapped an electron to change into $\mathrm{Fe}^{2+}$, thus demolishing the stable half filled electronic configuration. Thus for maintaining steady structure, the trapped electron could rapidly be transferred from $\mathrm{Fe}^{2+}$ to the oxygen molecules adsorbed on the surface of the photocatalyst and the $\mathrm{Fe}^{2+}$ recurred to the original half-filled state $\left(\mathrm{Fe}^{3+}\right)$, thus accelerating charge transfer and prohibiting the electron-hole recombination. Additionally, the titanium atoms could enter into the lattice and replaced $\mathrm{Ce}^{3+}$ or $\mathrm{Ce}^{4+}$, as the ionic radius of $\mathrm{Ti}^{4+}$ is much smaller than that of $\mathrm{Ce}^{3+}$ or $\mathrm{Ce}^{4+}$. This substitution led to a charge imbalance and to keep the equilibrium, more hydroxide ions were adsorbed onto the surface, thus benefiting the photogenerated electron-hole pairs separation, which eventually increased the photoactivity. Ling et al. [88], therefore, suggested that the cooperative actions of boron, ferrum, and cerium resulted in the increase of the photoactivity for degradation of DCP. Silija et al. [91] developed an efficient photocatalytic system with unique incorporation of carbon and nitrogen into $\mathrm{TiO}_{2}$, using urea as $\mathrm{N}$ precursor and ethanol as cosolvent. The systems, calcined at low temperature retained the carbon and showed excellent photoactivity. The coexistence of both the anion dopants, $\mathrm{C}$ and $\mathrm{N}$, enhanced the catalytic efficiency and was evident from the activity comparison studies. Surprisingly, this most photocatalytically active system, which was calcined at $300^{\circ} \mathrm{C}$, is found to be amorphous in nature and possesses highest surface area and lowest band gap among the prepared 
samples. The nitrogen was incorporated interstitially and it is found to be one of the best photocatalyst for $\mathrm{MB}$ degradation under visible light irradiation. Codoping of nanosilver, carbon, and nitrogen was done by Binitha et al. [92] on $\mathrm{TiO}_{2}$ to get efficient degradation in visible light for methyl orange degradation. Results showed a synergetic effect of carbon and nitrogen doping as well as nanosilver loading on the performance of $\mathrm{TiO}_{2}$. A dual-functional composite of nitrogen-doped $\mathrm{TiO}_{2}$ supported on activated carbon $\left(\mathrm{N}-\mathrm{TiO}_{2} / \mathrm{AC}\right)$ were prepared by Yap et al. [93]. Both adsorption and photocatalytic degradation effects of $\mathrm{N}-$ $\mathrm{TiO}_{2} / \mathrm{AC}$ were evaluated using bisphenol-A (BPA) as the target pollutant, in the aqueous phase. The effect of $\mathrm{pH}$ and influence of excitation wavelengths were investigated. Inhibition of BPA adsorption occurred at $\mathrm{pH} 11.0$ thus resulted in a slower kinetics of BPA photodegradation. N$\mathrm{TiO}_{2} / \mathrm{AC}$ was found to be photoresponsive under visible light (420-630 nm) illumination. Pt- and CdS-codoped $\mathrm{TiO}_{2}$ system $\mathrm{CdS} /\left(\mathrm{Pt} / \mathrm{TiO}_{2}\right)$ showed the highest rate of hydrogen production under visible light irradiation in comparison with $\mathrm{CdS} / \mathrm{TiO}_{2}$ or $\mathrm{Pt} / \mathrm{CdS}$ single component doped system due to the cooperation of the electron trapping ability of noble metal and decreased band gap energy due to the presence of CdS [94]. Similarly, the same observation had found in the case of Ag- and $\mathrm{InVO}_{4}$-codoped $\mathrm{TiO}_{2}$ composite thin film with $1 \% \mathrm{Ag}$ doping, where the system exhibited higher visible light photocatalytic activity for decomposition of aqueous methyl orange compared with $\mathrm{TiO}_{2}$ or $\mathrm{InVO}_{4}-$ $\mathrm{TiO}_{2}$ [95].

Yu et al. [96] reported visible light active catalyst with $\mathrm{Ga}$ and $\mathrm{W}$-codoped $\mathrm{TiO}_{2}$ with $\mathrm{Cu}^{2+}$ modification and found its quantum yield under visible light irradiation as $13 \%$. Many systems such as $\mathrm{CdS} / \mathrm{TiO}_{2}[97,98] . \mathrm{CdSe} / \mathrm{TiO}_{2}[99,100]$, $\mathrm{Bi}_{2} \mathrm{O}_{3} / \mathrm{SrTiO}_{3}$ [101], $\mathrm{Bi}_{2} \mathrm{~S}_{3} / \mathrm{TiO}_{2}$ [98, 102], $\mathrm{ZnMn}_{2} \mathrm{O}_{4} / \mathrm{TiO}_{2}$ [103], and $\mathrm{TiO}_{2} / \mathrm{Ti}_{2} \mathrm{O}_{3}$ [104] were formed sensitizer-loaded $\mathrm{TiO}_{2}$, which have shown efficient visible light photoactivity. In most of these catalysts, the addition of sensitizers reduced the band gap of the material and enhanced the visible light absorption. But the photogenerated holes of the sensitizer remain in the valence band (VB), and its accumulation leads to photocorrosion of the catalyst resulting in low stability of the composite photocatalyst [105].

3.2. $\mathrm{ZnO}$-Based Photocatalysts. Nanostructured $\mathrm{ZnO}$ is especially important in hi-tech applications owing to its unique chemical and physical properties [106, 107]. It is a direct wide gap and n-type semiconductor with a band-gap of $3.37 \mathrm{eV}$ and found to be useful in various opto-electronic applications such as light emitting diodes and solar cells, and so forth $[108,109]$. It is widely employed as a raw material in the textile, cosmetic, ceramic, and glass industries. Though $\mathrm{TiO}_{2}$ is the most extensively used photocatalyst [110], in recent years $\mathrm{ZnO}$ has attracted special attention owing to its low cost $[111,112]$, efficient synthesis, easy handling, reliability, and its application as a chemisensor and photocatalyst for the detection of toxic chemicals such as $\mathrm{H}_{2}, \mathrm{NH}_{3}$, liquid petroleum gas (LPG), HCHO, ammonium hydroxide, and alcohols, and so forth $[113,114]$. Moreover, $\mathrm{ZnO}$ has performance advantages over $\mathrm{TiO}_{2}$ for the decomposition of volatile organic compounds, including azo dyes [115]. ZnObased visible light photocatalyst seems to be an alternative to $\mathrm{TiO}_{2}$ and $\mathrm{WO}_{3}$ [116]. The energy levels for the conduction and valence bands and the electron affinity of zinc oxide are similar to those of $\mathrm{TiO}_{2}$, making $\mathrm{ZnO}$ a likely candidate as a semiconductor material for photocatalysis. Therefore, its photocatalytic ability had attracted much interest. $\mathrm{ZnO}$ has found to be a suitable alternative to $\mathrm{TiO}_{2}$ in a number of studies such as photodegradation of pesticides and herbicides [117], photocatalytic oxidation of pulp mill, bleaching waste water [118], degradation of 2,4,6-trichlorophenol [119] and 4-chlorophenol [120], photodegradation of Acid Red B dye [121] and degradation of cyanide, and so forth [122]. Poulios et al. [123] studied photocatalytic degradation of Auramine $\mathrm{O}$ in aqueous suspension using $\mathrm{ZnO}$ and $\mathrm{TiO}_{2}$ separately in a batch reactor, and they concluded that the rate of degradation of pollutants is faster with $\mathrm{ZnO}$ than with $\mathrm{TiO}_{2}$ (Degussa P25). Its low efficiency of photocatalysis and low stability due to photocorrosion are the two main drawbacks facing by these $\mathrm{ZnO}$ photocatalysts compared with the common photocatalyst, $\mathrm{TiO}_{2}$. The principal advantage of $\mathrm{ZnO}$ is that it absorbs over a larger fraction of solar spectrum than $\mathrm{TiO}_{2}$ [124].

Many efforts have been made to develop $\mathrm{ZnO}$-based visible light photocatalysts, particularly, combination with GaN [125] or Co doping [126] into $\mathrm{ZnO}$, to extend the absorption spectrum of $\mathrm{ZnO}$ to the visible region. Efficient $\mathrm{ZnO}$-based visible light photocatalysts, $\mathrm{Cu}(\mathrm{II})$-modified $\mathrm{Cd}_{x} \mathrm{Zn}_{1-x} \mathrm{O}$, were developed by adopting a hybrid approach, consisting of band-engineering by formation of a solid solution and multielectron reduction by the modification of cocatalysts by Anandan et al. [116]. Due to the similar physical characteristics of $\mathrm{Cd}^{2+}$ and $\mathrm{Zn}^{2+}$, a substitution of $\mathrm{Zn}^{2+}$ by $\mathrm{Cd}^{2+}$ results in the visible light absorption without the formation of defects. $\mathrm{Cd}_{x} \mathrm{Zn}_{1-x} \mathrm{O}$ showed high photocatalytic activities under visible light illumination as compared to pure $\mathrm{ZnO}$ for the decomposition of gaseous acetaldehyde. Further, $\mathrm{Cu}^{2+}$ modification ensures the enhancement in the visible light activity of $\mathrm{Cd}_{x} \mathrm{Zn}_{1-x} \mathrm{O}$ by capturing the photoexcited electrons [116]. A novel approach to the oxidative degradation of toluene, salicylic acid, and 4-chlorophenol using a specially designed photoelectrochemical detoxification reactor with $\mathrm{ZnO}$ electrodes under solar radiation has been proposed by Shinde et al. [127]. Pardeshi and Patil [128] had investigated the photocatalytic degradation of resorcinol, a potent endocrine disrupting chemical, in aqueous medium using $\mathrm{ZnO}$ under sunlight irradiation in a batch photoreactor. Resorcinol solutions of lower concentration were completely mineralized by photocatalytic degradation on the surface of $\mathrm{ZnO}$ under irradiation of sunlight, and the degradation was found to be favorable in neutral and basic solutions.

The $\mathrm{ZnO} / \mathrm{Cu}_{2} \mathrm{O}$ compound photocatalysts were prepared by $\mathrm{Xu}$ et al. [129] using "soak-deoxidize-air oxidation" method. The prepared $\mathrm{ZnO} / \mathrm{Cu}_{2} \mathrm{O}$ compound showed absorption in the visible light region, between 400 and $610 \mathrm{~nm}$. All the $\mathrm{ZnO} / \mathrm{Cu}_{2} \mathrm{O}$ compounds have higher photocatalytic activity than pure $\mathrm{ZnO}$, and some compounds are better than pure $\mathrm{Cu}_{2} \mathrm{O}$. The degradation of $\mathrm{MO}$ reached $73 \%$ after $180 \mathrm{~min}$ of reaction when the $\mathrm{ZnO} / \mathrm{Cu}_{2} \mathrm{O}$ compound 
(the mole ratio of $\mathrm{Cu}_{2} \mathrm{O}$ to $\mathrm{ZnO}$ was 0.138 ) was used as photocatalyst. Kanade et al. [5] reported a new approach for the synthesis of lattice-doped copper in the nanocrystalline wurtzite $\mathrm{ZnO}$ in different solvents, and their use as a photocatalyst for the decomposition of $\mathrm{H}_{2} \mathrm{~S}$ to generate hydrogen. The average particle size was found to be in the range of $40-85 \mathrm{~nm}$. The maximum hydrogen production rate achieved was $1932 \mu \mathrm{mol} \mathrm{h}^{-1}$ over the as synthesized $\mathrm{Cu}$ doped $\mathrm{ZnO}$ by $\mathrm{H}_{2} \mathrm{~S}$ decomposition under visible light irradiation. There, $\mathrm{Cu}$ doped $\mathrm{ZnO}$ acts as a photocathode, and adsorption of light promoted electrons in the conductance band $(\mathrm{CB})$ of semiconductor where the potential $(-0.88 \mathrm{~V})$ was sufficient to liberate hydrogen. At the same time, holes in the valence band (VB) moved into the bulk to facilitate the oxidation process, where they were transferred to the reduced species $\mathrm{S}^{2-}$, which acts as a hole-scavenger and prevented the photocorrosion of the photocatalyst. In their study, it was observed that the visible light photocatalytic activity of $\mathrm{Cu}-\mathrm{ZnO}$ synthesized in organic media was higher when compared to that synthesized in water medium due to well-crystallined self-aligned particles. Chen et al. [130] modified $\mathrm{ZnO}$ photocatalysts with thiourea to enhance their photocatalytic activity by nonmetal dopants under visible light illumination. The photocatalytic activity of modified $\mathrm{ZnO}$ had also been examined for the degradation of $\mathrm{AO} 7$ and phenol under UV and visible light illumination. N-, S-, and $\mathrm{C}$-doped $\mathrm{ZnO}(\mathrm{N}, \mathrm{S}, \mathrm{C}-\mathrm{ZnO})$ particles were synthesized from thiourea and zinc sulfate via precipitation method. The visible light activity of the $\mathrm{N}, \mathrm{S}, \mathrm{C}-\mathrm{ZnO}$ samples was confirmed by degradation of phenol. The optimal molar ratios of thiourea to zinc sulfate were 1 and 2 for the highest photocatalytic activities under UV and visible light illumination, respectively. The $500^{\circ} \mathrm{C}$-calcined N, S and C$\mathrm{ZnO}$ showed strong photoabsorbance in the visible light region.

Pardeshi et al. [131] had synthesized $\mathrm{ZnO}$ crystallites by two-steps solution-free mechanochemical method for the complete mineralization of resorcinol solutions of $100 \mathrm{ppm}$ concentration by photocatalytic degradation under sunlight irradiation. Li and Haneda [132] reported the synthesize of two series of $\mathrm{N}$-containing $\mathrm{MO}_{x}-\mathrm{ZnO}$ composite powders $\left(\mathrm{WO}_{3}-\mathrm{ZnO}\right.$ and $\left.\mathrm{V}_{2} \mathrm{O}_{5}-\mathrm{ZnO}\right)$ by spray pyrolysis. Acetaldehyde photodecomposition was used as a probe reaction to evaluate their photocatalytic activity. The $\mathrm{MO}_{x}$ addition enhanced the photocatalytic activity of the N-containing $\mathrm{ZnO}$ powder under both UV and visible light irradiation. This enhancement under visible light is due to a synergistic effect of $\mathrm{N}$-doping and $\mathrm{MO}_{x}-\mathrm{ZnO}$ coupling. The $\mathrm{N}$ doping induced the formation of an electronic impurity level in the band structure of $\mathrm{ZnO}$; therefore, the electron transition from valence band to conduction band in a $\mathrm{ZnO}$ semiconductor could be achieved through two-step transitions even with the lower energy of visible light. $\mathrm{ZnO}$ has emerged to be a more efficient catalyst concerning water detoxification in an efficient way. Also it has more number of surface active sites with high surface reactivity. Due to its lowprice, very simple synthesis process, biocompatibility nature, high-stability, high-activity towards photo-induced redox reactions, various applications in photonics and electronics, photocatalytic reduction, the eradication of environmental pollutants, it is predicted that $\mathrm{ZnO}$ as well as modified $\mathrm{ZnO}$ could be one of the best photo-catalysts for the degradation of organic dyes and other pollutants.

3.3. Tantalum Oxide, Tantalum Nitride, and Tantalum Oxynitride. As a typical semiconductor, tantalum oxide $\left(\mathrm{Ta}_{2} \mathrm{O}_{5}\right)$ has attracted increasing interests due to its superior properties, such as good chemical resistance, high melting point, and photocatalytic activity under UV irradiation [133]. Recently, it is identified that the tantalum oxynitride and tantalum nitride are potential photocatalysts that function under visible light irradiation [134]. Tantalum (V) nitride, with an optical band gap of $2.08 \mathrm{eV}$ [135], is found to be an efficient photocatalyst in the visible region of the electromagnetic spectrum, with a quantum efficiency of ca. $10 \%$ for overall water splitting and showed good hydrolytic stability [134]. Tantalum nitride with an anosovite structure [136] has been studied as a $600 \mathrm{~nm}$ light-absorbing photocatalyst [134, 137] and as a photoanode for water splitting reactions [138]. The conduction band of $\mathrm{Ta}_{3} \mathrm{~N}_{5}$ is composed of vacant Ta $5 \mathrm{~d}$ states, and the valence band consists of occupied N 2p orbitals. The conduction bands of tantalates consisting of a tantalum (Ta $5 \mathrm{~d}$ ) orbital located at more negative potential than titanates $(\mathrm{Ti} 3 \mathrm{~d})$ and niobates ( $\mathrm{Nb} 4 \mathrm{~d})$ [139], Maeda et al. [140] attempted to increase the photocatalytic activity of tantalum oxynitride ( $\mathrm{TaON}$ ) for $\mathrm{H}_{2}$ evolution under visible light by reducing the particle size, since smaller particle size usually results in a shorter diffusion length for photogenerated electron-hole pairs in a given photocatalyst. Tantalum oxynitride ( $\mathrm{TaON})$ and tantalum nitride $\left(\mathrm{Ta}_{3} \mathrm{~N}_{5}\right)$ are investigated in detail as visible light driven photocatalyst for overall splitting of water. $\mathrm{The} \mathrm{Ta}_{3} \mathrm{~N}_{5}$ is found to be in red $\left(E_{g}=2: 08 \mathrm{eV}\right)$, whereas $\mathrm{TaON}$ is in yellow colour $(2.5 \mathrm{eV})$ [141]. It was found that $\mathrm{TaON}$ and $\mathrm{Ta}_{3} \mathrm{~N}_{5}$ evolved $\mathrm{H}_{2}$ or $\mathrm{O}_{2}$, respectively, in the presence of a sacrificial electron donor or acceptor, via band gap excitation. The band gap energies of $\mathrm{Ta}_{2} \mathrm{O}_{5}, \mathrm{TaON}$, and $\mathrm{Ta}_{3} \mathrm{~N}_{5}$ are to be 3.9, 2.5 and $2.1 \mathrm{eV}$, respectively. This band gap narrowing occurs by substituting nitrogen for oxygen in these oxides since nitrogen has a lower electronegativity than oxygen and the presence of $\mathrm{O}^{2-}$ in the anionic framework will increase the band gap. As the electronic potential of the $\mathrm{N} 2 \mathrm{p}$ orbitals is higher than that of $\mathrm{O} 2 \mathrm{p}$, it is expected that the $\mathrm{N} 2 \mathrm{p}$ orbitals will dominate the occupancy of the top of the valence band, leading to band-gap narrowing [135]. Thus the electronic structural changes in the valenceband states may occur as a result of the incorporation of nitrogen. Density functional theory (DFT) calculations showed that the upper part of the valence band is dominated by $\mathrm{N} 2 \mathrm{p}$ orbitals on account of the higher potential energy of the $\mathrm{N} 2 \mathrm{p}$ orbital compared to the O $2 \mathrm{p}$ orbital [135]. Luan et al. [142] synthesized new pyrochlore-type structure compounds $\mathrm{Bi}_{2} \mathrm{GaTaO}_{7}$ and $\mathrm{Ga}_{2} \mathrm{BiTaO}_{7}$ by solid-state (SS) reaction methods and evaluated photocatalytic properties for the degradation of $\mathrm{MB}$ dye under ultraviolet and visible light irradiation. A systematic study of the structural, morphological, optical, and visible light photocatalytic properties of Tadoped $\mathrm{ZnO}$ and pure $\mathrm{ZnO}$ samples has been carried out by 
Kong et al. [143]. The Ta doping also changes the morphology, surface adsorption, specific surface area, crystalline size and increases the lattice constants and band gap of the nanocrystals. The photocatalytic efficiency of the Ta-doped $\mathrm{ZnONPs}$ is much more excellent than the pure $\mathrm{ZnO}$ and is attributed to the increase of the active hydrogen-related defect sites caused by $\mathrm{Ta}^{5+}$ doping, leading to the enhanced specific surface area and optical absorption in the visible light region [143]. Zhang et al. [144] successfully synthesized a novel, nanosized, $\mathrm{Bi}_{3}-\mathrm{TaO}_{7}$ photocatalyst which showed a strong optical absorption in the visible light region $(k>$ $400 \mathrm{~nm}$ ) and a high adsorption ability for the 4 BS dye. They had evaluated the photocatalytic properties of the $\mathrm{Bi}_{3} \mathrm{TaO}_{7}$ nanopowders, by the degradation of $4 \mathrm{BS}$ aqueous solution under visible light irradiation. It has also been found that niobium and tantalum ions are efficient codopants to maintain the charge balance when titanate photocatalysts are modified by doping with the low valence ions such as $\mathrm{Cr}^{3+}$ [145]. Because of all the above mentioned incentives, in recent years, Ta-based compounds will get more exposure to the field of photocatalysis.

3.4. $\mathrm{Fe}_{2} \mathrm{O}_{3}$-Based Photocatalysts. $\mathrm{Fe}_{2} \mathrm{O}_{3}$ exists widely in nature and is an environmentally friendly n-type semiconductor $\left(E_{g}=2.1 \mathrm{eV}\right)$. It is an important functional material because of its applications (e.g., magnetic and catalytic properties, chemical stability, biocompatibility, low toxicity), and so forth. It is widely used in catalysts, pigments, sensors, photoelectrodes for solar energy conversion, clinical therapy and diagnosis and as a raw material for synthesizing other compounds [146-149]. Most of the iron oxides have been revealed as photochemically active [150], and its incorporation with $\mathrm{TiO}_{2}$ not only efficiently inhibits the recombination between the photo-generated electrons and holes, but also enhances the absorption of solar light $[19,151-154]$. In recent years, it has been found that the composites of $\mathrm{TiO}_{2}$ and $\mathrm{Fe}_{2} \mathrm{O}_{3}$ can effectively respond to visible light $[88,155]$ due to the narrow band-gap of $\mathrm{Fe}_{2} \mathrm{O}_{3}$. It has also been reported that when $\mathrm{Fe}_{3} \mathrm{O}_{4}$, reacted with $\mathrm{TiO}_{2}$ powders and produced $\mathrm{Fe}$ containing $\mathrm{TiO}_{2}$ compounds, such as $\mathrm{FeTiO}_{3}$, the electrons in the valence bands of $\mathrm{FeTiO}_{3}$ are excited to the conduction band of $\mathrm{FeTiO}_{3}$ first, and then will get promoted to the conduction band of $\mathrm{TiO}_{2}$. This leads to an improved photocatalytic activity due to the decrease of electron recombination [156]. Iron, as a dopant in $\mathrm{TiO}_{2}$-based systems, has been investigated to enhance the photocatalytic efficiency under visible light irradiation to counter the potential negative environmental problems of using heavy metal sensitizers [157-161].

Transparent $\alpha-\mathrm{Fe}_{2} \mathrm{O}_{3}$ films were synthesized [162] with varying thickness of film on an $\mathrm{SnO}_{2}$ transparent conducting film-coated glass substrate by metal organic deposition. It showed high photocatalytic activity for the decomposition of 2-naphthol with visible light irradiation under anodicbiased conditions. The $\alpha-\mathrm{Fe}_{2} \mathrm{O}_{3}$ was transformed to inactive $\mathrm{Fe}(\mathrm{OH})_{3}$ as the reaction proceeded, while the activity was always maintained in acetonitrile. Methylene blue was chosen as a model pollutant for testing the photocatalytic activity of the p-n junction photocatalyst $\mathrm{p}-\mathrm{CaFe}_{2} \mathrm{O}_{4} / \mathrm{n}-\mathrm{Ag}_{3} \mathrm{VO}_{4}$ prepared by ball milling $\mathrm{Ag}_{3} \mathrm{VO}_{4}$ in $\mathrm{H}_{2} \mathrm{O}$ doped with ptype $\mathrm{CaFe}_{2} \mathrm{O}_{4}$ [163]. The visible light irradiation results showed that the photocatalytic activity of the p- $\mathrm{CaFe}_{2} \mathrm{O}_{4} / \mathrm{n}-$ $\mathrm{Ag}_{3} \mathrm{VO}_{4}$ was higher than that of $\mathrm{Ag}_{3} \mathrm{VO}_{4}$. The $2.0 \mathrm{wt} . \%$ p-CaFe ${ }_{2} \mathrm{O}_{4}$ doped $\mathrm{p}-\mathrm{CaFe}_{2} \mathrm{O}_{4} / \mathrm{n}-\mathrm{Ag}_{3} \mathrm{VO}_{4}$, which was ball milled for $12 \mathrm{~h}$, showed $85.4 \%$ photocatalytic degradation. Since $\mathrm{CaFe}_{2} \mathrm{O}_{4}$ is a p-type semiconductor, and $\mathrm{Ag}_{3} \mathrm{VO}_{4}$, an n-type semiconductor, the photogenerated electrons and holes separation is efficient, to show better photocatalytic activity. Highly ordered $\mathrm{ZnFe}_{2} \mathrm{O}_{4}$ nanotube arrays were successfully prepared by anodic $\mathrm{Al}_{2} \mathrm{O}_{3}$ templates from solgel solution, and its photocatalytic capability under visible light irradiation was evaluated [164], using 4-chlorophenol as the model contaminant, which constitutes an important class of soil and water pollutants arising from their wide use as pesticides, herbicides, and wood preservatives.

$\mathrm{Fe}_{2} \mathrm{O}_{3}-\mathrm{TiO}_{2}$ composite photocatalyst was synthesized by an ethanol-assisted hydrothermal method, from $\mathrm{Fe}_{2}\left(\mathrm{SO}_{4}\right)_{3}$ and $\mathrm{Ti}\left(\mathrm{SO}_{4}\right)_{2}$ [165]. The presence of $\alpha-\mathrm{Fe}_{2} \mathrm{O}_{3}$ and anatase $\mathrm{TiO}_{2}$ in the composites was confirmed from the results. This sample led to a photodegradation efficiency of $90 \%$ and $40 \%$ of auramine, under visible light and solar light, respectively, and it was significantly higher than that of pure $\mathrm{TiO}_{2}$. The optimal photocatalyst contains $1: 2$ for molar ratio of $\mathrm{Ti}$ to $\mathrm{Fe}$, and it exhibited the highest photocatalytic degradation efficiency of auramine. With further increase in the ratio to $1: 4$, the degradation efficiency on the organic dye decreased slightly. The $\mathrm{Fe}_{2} \mathrm{O}_{3}-\mathrm{TiO}_{2}$ synthesized under optimum condition $(2 \mathrm{~h}$ reaction time, $160^{\circ} \mathrm{C}$ reaction temperature, $20 \%$ for the volume fraction of ethanol) consisted of mesoporous structure with an average pore size of $4 \mathrm{~nm}$ and a surface area of $43 \mathrm{~m}^{2} / \mathrm{g}$. Sulfated $\mathrm{Fe}_{2} \mathrm{O}_{3}-\mathrm{TiO}_{2}$ (SFT) was synthesized by Smith et al. [166], and photocatalytic activity was evaluated by the oxidation of 4-chlorophenol (4-CP) in aqueous medium under UV and visible light irradiation. The SFT calcined at $500^{\circ} \mathrm{C}$ demonstrated the highest photocatalytic activity, and it possessed a band gap value of $2.73 \mathrm{eV}$. Despite of the low surface area of the SFT samples, $\left(12-17 \mathrm{~m}^{2} / \mathrm{g}\right)$ compared with the surface area of sulfated $\mathrm{TiO}_{2}\left(275 \mathrm{~m}^{2} / \mathrm{g}\right)$, the better photocatalytic activity was due to the presence of iron. These observations revealed the significance of the presence of iron in $\mathrm{TiO}_{2}$ for photocatalytic activity. So in view of the efficient utilization of solar light, the $\alpha-\mathrm{Fe}_{2} \mathrm{O}_{3}$ (hematite), with narrow band gap had been explored as photocatalysts, and it has been investigated for its photochemical behavior as a semiconductor electrode.

\subsection{A Glance to the Photoactivity of Other Metal Oxides.} Tremendous efforts have been dedicated to synthesize monoclinic $\mathrm{BiVO}_{4}\left(\mathrm{~m}-\mathrm{BiVO}_{4}\right)$ owing to its fascinating structurerelated properties after the first report of the preparation of bismuth vanadate crystals in 1925 [167]. The key factors in determining the photocatalytic activity of $\mathrm{m}-\mathrm{BiVO}_{4}$ are its optical absorption properties, which are related to its electronic structure $[168,169]$. The crystal structure of $\mathrm{m}-$ $\mathrm{BiVO}_{4}$, with its calculated band gap of $2.2 \mathrm{eV}$, makes it a promising, nontoxic, visible light responsive photocatalyst [170], for the degradation of harmful pollutants and as a 
thermochromic material for indicating temperature [170172]. $\mathrm{BiVO}_{4}$ is found to be one of the photocatalysts that exhibits high activity for photocatalytic $\mathrm{O}_{2}$ evolution under visible light irradiation $[173,174]$. Due to the low band gap $(2.4-2.5 \mathrm{eV})[175]$ and reasonable band edge alignment with respect to the water redox potentials, it has shown particular promise for water photodecomposition. In addition to high photon-to-current conversion efficiencies ( $>40 \%$ ) [175], the system shows both $\mathrm{n}$ - and $\mathrm{p}$-type semiconducting properties [176]. It has been reported that the $\mathrm{BiVO}_{4}$ is found to be a direct band gap semiconductor, despite having band extrema away from the Brillouin zone center [177]. The direct gap is maintained via coupling between $V 3 d, O 2 p$, and $\mathrm{Bi} 6 \mathrm{p}$, which lowered the conduction band minimum. DFT calculations suggested that the hybridization of $\mathrm{Bi} 6 \mathrm{~s}$ and $\mathrm{O} 2 \mathrm{p}$ levels resulted in the valence band which favors the mobility of photo-excited holes and, thus, enhanced the photocatalytic oxidation of organic pollutants [168].

$\mathrm{SrTiO}_{3}$ is one of the best host materials for the design of visible light driven photocatalysts, possessing the $\mathrm{H}_{2}$ production ability, by transition metal ion doping. Kudo and Hijii [178] and Tang et al. [179] studied the activity of a potential, visible light responsive photocatalyst, $\mathrm{Bi}_{2} \mathrm{WO}_{6}$, the simplest member in the Aurivillius family, for the first time. Their study revealed that $\mathrm{Bi}_{2} \mathrm{WO}_{6}$ could perform as an excellent photocatalyst and solar energy transfer material. It was demonstrated that the visible light photocatalytic activity of $\mathrm{Bi}_{2} \mathrm{WO}_{6}$, which has a novel octahedron-like hierarchical structure, in the degradation of Rhodamine $\mathrm{B}(\mathrm{RhB})$, was better when compared to that of the $\mathrm{Bi}_{2} \mathrm{WO}_{6}$ synthesized by solid-state reaction (SSR) [180]. When the $\mathrm{pH}$ value of $\mathrm{Bi}_{2} \mathrm{WO}_{6} / \mathrm{RhB}$ suspension was 7.5 , the photodegradation was apparently enhanced and $95 \%$ of the $\mathrm{RhB}$ could be degraded after $6 \mathrm{~h}$, which had shown the $\mathrm{pH}$ dependence of the prepared catalyst. Recently, a novel series of $\mathrm{InMO}_{4}(\mathrm{M}$ $=\mathrm{Nb}, \mathrm{Ta}, \mathrm{V}$ ) catalysts was reported to show high activity for water splitting reaction under visible light $[181,182]$.

Konta et al. [183] reported that $\mathrm{Ag}_{3} \mathrm{VO}_{4}$ showed a competent activity for the evolution of $\mathrm{O}_{2}$ from an aqueous silver nitrate solution under visible light irradiation. Since then silver vanadate $\left(\mathrm{Ag}_{3} \mathrm{VO}_{4}\right)$ material had attracted much attention [184-187]. It has been reported that $\mathrm{WO}_{3}[188$, 189], $\mathrm{RbPb}_{2} \mathrm{Nb}_{3} \mathrm{O}_{10}$ [188], $\mathrm{BiVO}_{4}\left[188,189\right.$ ], $\mathrm{Bi}_{2} \mathrm{WO}_{6}$ [189], chromium/antimony-doped $\mathrm{TiO}_{2}$ [190], $\mathrm{AgNbO}_{3}$ [191], and $\mathrm{Ag}_{3} \mathrm{VO}_{4}$ [183] are visible light driven photocatalysts for the evolution of $\mathrm{O}_{2}$ from water, containing a sacrificial reagent. $\mathrm{Pt} / \mathrm{HPb}_{2} \mathrm{Nb}_{3} \mathrm{O}_{10}$ [188] and chromium/antimonydoped $\mathrm{SrTiO}_{3}$ [190] were also found to be active metal oxides. Recently, a simple pristine metal oxide tungsten oxide $\left(\mathrm{WO}_{3}\right)$ is reported as a visible light driven photocatalyst because of its small band-gap $(2.8 \mathrm{eV})$ and a deeper $\mathrm{VB}$ $(+3.1 \mathrm{~V}$ versus SHE, $\mathrm{pH} 0)$. Though the $\mathrm{WO}_{3}$ is a good candidate for visible light active photocatalysts, tungsten is a rare metal with high cost, and $\mathrm{WO}_{3}$ is chemically unstable especially in alkaline solution. The visible light activity of $\mathrm{WO}_{3}$ was greatly enhanced via efficient oxygen reduction process by the addition of cocatalysts, such as Pt [192], $\mathrm{Cu}^{2+}$ [193], Pd [194], or Tungsten Carbide (WC) [195], where the cocatalysts acted as electron pools to initiate multielectron reductions. The quantum yield obtained for the decomposition of gaseous iso-propanol using $\mathrm{WO}_{3}$ was $17 \%$ [193], which is much higher than that obtained with nitrogen-doped $\mathrm{TiO}_{2}$ [51]. Thus, a metal oxide with low conduction band, like $\mathrm{WO}_{3}$, can be used as a promising candidate for visible light active photocatalysts, by modifying its surface with co-catalysts like $\mathrm{Cu}^{2+}$ ions that can help in multielectron reduction. Table 1 also discusses a number of important visible light photocatalysts.

\section{Different Means for the Reduction of Band Gaps}

The mixing effect of band gaps of the composite semiconductor leads to large red shift. Cheng et al. [196] stated that when a relatively broad band gap anatase $\mathrm{TiO}_{2}$ was mixed with a narrow band gap zinc ferrite, the band gap of composite semiconductor would locate between the band gaps of these two semiconductors, that is, it shifts to a lower energy, as compared with that of $\mathrm{TiO}_{2}$. Due to the interfacial coupling effect, the zinc ferrite could induce lattice defects on the surface of $\mathrm{TiO}_{6}$ octahedra, which will serve as the centres of bound excitons, which is another factor that resulted in large red shift [197].

Hur et al. [198] reported that the incorporation of $\mathrm{Pb}$ or $\mathrm{Sn}$ ions led to a distinct depression of the $E_{g}$ value of ternary metal oxide $\operatorname{Sr}\left(\operatorname{In}_{1 / 2} \mathrm{Nb}_{1 / 2}\right) \mathrm{O}_{3}$, which is a UVactive semiconductor with a wide bandgap separation of $3.6 \mathrm{eV}$ to $3.1 \mathrm{eV}$ for $\mathrm{Pb}$ and $3.5 \mathrm{eV}$ for $\mathrm{Sn}$. A similar trend in the variation of bandgap energy was also observed for the Ba-based compounds upon B-site cation substitution in $\mathrm{A}\left(\mathrm{In}_{1 / 3} \mathrm{Nb}_{1 / 3} \mathrm{~B}_{1 / 3}\right) \mathrm{O}_{3}$ with $\mathrm{Pb}$ and $\mathrm{Sn}$. The band gap energy $(3.30 \mathrm{eV})$ of $\mathrm{Ba}\left(\operatorname{In}_{1 / 2} \mathrm{Nb}_{1 / 2}\right) \mathrm{O}_{3}$ showed a depression of 3 and 1.48 , respectively, for $\mathrm{Sn}$ and $\mathrm{Pb}$. The lead-substituted $\mathrm{A}\left(\mathrm{In}_{1 / 3} \mathrm{Nb}_{1 / 3} \mathrm{~Pb}_{1 / 3}\right) \mathrm{O}_{3}$ compounds resulted in more effective decomposition of MB, under UV-vis $(\lambda>300 \mathrm{~nm})$ radiations compared to the pristine $\mathrm{A}\left(\mathrm{In}_{1 / 2} \mathrm{Nb}_{1 / 2}\right) \mathrm{O}_{3}$. The $\mathrm{Ba}\left(\operatorname{In}_{1 / 3} \mathrm{Nb}_{1 / 3} \mathrm{~Pb}_{1 / 3}\right) \mathrm{O}_{3}$ compound induced an effective degradation of 4-chloro phenol under visible light radiation $(\lambda>420 \mathrm{~nm})$, whereas there was no significant change in 4-chloro phenol concentration when exposed to $\operatorname{Sr}\left(\operatorname{In}_{1 / 3} \mathrm{Nb}_{1 / 3} \mathrm{~Pb}_{1 / 3}\right) \mathrm{O}_{3}$. A series of $\mathrm{InVO}_{4}$ and $\mathrm{NiO} / \mathrm{InVO}_{4}$ catalysts were prepared by Lin et al. [199] with a lower band gap of $1.8 \mathrm{eV}$ for $\mathrm{InVO}_{4}$ which is consistent with the result reported by Ye et al. [181], where they had obtained $\mathrm{InVO}_{4}$ band gap as $1.9 \mathrm{eV}$. The small band gap of these catalysts indicates its ability to split water into $\mathrm{H}_{2}$ and $\mathrm{O}_{2}$ in visible light. Loading of $\mathrm{NiO}$ significantly increases the adsorption of visible light and the $1 \% \mathrm{NiO}$ loaded $\mathrm{InVO}_{4}$ showed a highest absorbance in visible light region and exhibited highest photocatalytic activity for water splitting. kudo et al. [200] developed an efficient visible light driven photocatalyst $\mathrm{Zn}_{1-x} \mathrm{Cu}_{x} \mathrm{~S}$ for the evolution of $\mathrm{H}_{2}$ from an aqueous $\mathrm{Na}_{2} \mathrm{SO}_{3}$ solution. They had succeeded to get a quantum yield of $3.7 \%$ at $420 \mathrm{~nm}$, without a co-catalyst such as Pt. ZnS photocatalysts, which possess a band gap of $3.7 \mathrm{eV}$ ( $\alpha$ phase: $3.8 \mathrm{eV}$, $\beta$ phase: $3.6 \mathrm{eV}$ ), have an absorption band only in the UV region, whereas the absorption edge of the $\mathrm{Zn}_{0.957} \mathrm{Cu}_{0.043} \mathrm{~S}$ solid solution reached to the visible light region around 
TABLE 1: Some visible light responsive photocatalysts.

\begin{tabular}{|c|c|c|}
\hline Catalyst & Photocatalytic reaction & Reference \\
\hline $\begin{array}{l}\mathrm{Zn}_{1-x} \mathrm{Cu}_{x} \mathrm{~S} \text { solid } \\
\text { solution }\end{array}$ & $\begin{array}{l}\text { The } \mathrm{H}_{2} \text { evolution reaction from an aqueous solution of } \mathrm{Na}_{2} \mathrm{SO}_{3} \text { were performed and got } \\
\text { a quantum yield of } 3.7 \% \text { at } 420 \mathrm{~nm} \text {. }\end{array}$ & {$[200]$} \\
\hline $\begin{array}{l}\text { zinc ferrite doped } \\
\mathrm{TiO}_{2} \text { (ZFDT) }\end{array}$ & $\begin{array}{l}\text { ZFDT powders effectively photodegraded methyl orange under visible light irradiation } \\
\text { and achieved maximum photoactivity when the amount of zinc ferrite was } 1.5 \% \text {. }\end{array}$ & [196] \\
\hline $\begin{array}{l}\text { zeolite-based } \\
\text { composite }\end{array}$ & $\begin{array}{l}\text { Showed high efficiency when compared to } \mathrm{TiO}_{2} \text { photocatalyst for photoreduction of water } \\
\text { to hydrogen in the visible light range with the combination of } \mathrm{Co}^{2+}, \mathrm{TiO}_{2} \text { and heteropoly } \\
\text { acid. }\end{array}$ & {$[222]$} \\
\hline $\mathrm{N}$-doped $\mathrm{TiO}_{2}$ & $\begin{array}{l}\text { The colloidal } \mathrm{TiO}_{2} \text { nanoparticles treated with triethylamine by a batch system was found } \\
\text { to show particularly efficient photocatalytic activity under visible illumination. }\end{array}$ & {$[223]$} \\
\hline $\begin{array}{l}\text { m-BiVO } 4 \text { quantum } \\
\text { tubes }\end{array}$ & Photodegradation of $\mathrm{RhB}$ reached $98.7 \%$ after 15 min irradiation & {$[224]$} \\
\hline $\mathrm{N}-\mathrm{TiO}_{2}$ & The photocatalytic degradation of trichloroethylene was well-reproduced several times. & [225] \\
\hline $\mathrm{CoTa}_{2} \mathrm{O}_{6}$ & $\begin{array}{l}\mathrm{H}_{2} \text { is produced from aqueous } \mathrm{CH}_{3} \mathrm{OH} \text { solution using Pt-loaded powder samples and } \mathrm{O}_{2} \\
\text { from aqueous } \mathrm{AgNO}_{3} \text { solution under visible light irradiation. }\end{array}$ & {$[226]$} \\
\hline $\begin{array}{l}\mathrm{InVO}_{4} \text { and } \\
\mathrm{NiO} / \mathrm{InVO}_{4}\end{array}$ & $\begin{array}{l}\text { The } 1 \% \mathrm{NiO} / \mathrm{InVO}_{4} \text { catalyst which was reduced at } 500^{\circ} \mathrm{C} \text { and oxidized at ambient } \\
\text { condition for } 48 \mathrm{~h} \text { gave the highest activity with a rate of } 896 \mu \mathrm{mol} \mathrm{h}^{-1} \mathrm{~g}^{-1} \text {. }\end{array}$ & {$[199]$} \\
\hline $\mathrm{BiVO}_{4}$ & $\begin{array}{l}\text { Showed good } \mathrm{O}_{2} \text { evolution activity over } \mathrm{BiVO}_{4} \text { nano-leaves by photocatalytic water } \\
\text { splitting under visible light irradiation }\end{array}$ & {$[227]$} \\
\hline
\end{tabular}

$500 \mathrm{~nm}$ and the energy gap of the $\mathrm{Zn}_{0.957} \mathrm{Cu}_{0.043} \mathrm{~S}$ solid solution was estimated to be $2.5 \mathrm{eV}$. Because of the improper position of conduction band edge $(-0.45 \mathrm{~V}), \mathrm{WO}_{3}$ did not show photocatalytic activity for water splitting. Hwang et al. [201] reported that doping of $5-10 \% \mathrm{Mg}$ in $\mathrm{WO}_{3}$ showed improved photocatalytic activity for water splitting, where the conduction band level was shifted leading to a band gap of $-2.7 \mathrm{~V}$. $\mathrm{ZnFe}_{2} \mathrm{O}_{4}$ is another catalyst with a relatively small band gap $(1.9 \mathrm{eV})$, which was used as an effective photocatalyst due to its capability of utilizing visible light and good photochemical stability $[202,203]$. So the band gap narrowing is an efficient method to shift the absorption edge of a photocatalyst to visible light region of the spectrum.

\section{Effect of Preparation Method on the Activity of Visible Light Driven Photocatalysts}

Numerous efforts have been postulated for the fabrication and application of efficient semiconductor manufacture. Photoactivity is highly dependent on surface area, crystallinity, or crystal sizes, which in turn is influenced by the synthetic method [204]. As far as such methods are concerned, hydrothermal, sol-gel, impregnation, chemical vapour deposition, and coprecipitation are most widely used.

5.1. Sol-Gel Method. Sol-gel technology is a low-temperature method of preparing inorganic materials by chemical routes. Many researchers had paid attention in synthesizing new photocatalysts. Among the various methods, sol-gel method has attracted most attention because of low process cost, easy control of composition, and relatively low calcination temperatures. Here we evaluate some promising reports of visible active photocatalysts prepared via sol-gel method.

Jung et al. [205] have synthesized $\mathrm{Al}_{2} \mathrm{O}_{3}-\mathrm{TiO}_{2}$ solid solution by sol-gel method via adjusting the $\mathrm{pH}$ and it is used for the decomposition of acetaldehyde under visible light. Here, anatase phase was maintained even after calcination at $800^{\circ} \mathrm{C}$, and the BET surface area for mixed oxides $\left(116.8 \mathrm{~m}^{2} / \mathrm{g}\right)$ was much higher than either that of pure $\mathrm{TiO}_{2}$ or $\mathrm{Al}_{2} \mathrm{O}_{3}$. They attained a maximum conversion of acetaldehyde for $\mathrm{Ti}(70 \%)-\mathrm{Al}(30 \%)$ mixed oxide, that is, $79 \%$ for $2 \mathrm{~h}$ reaction. Parida et al. [206] prepared, sulfatemodified $\mathrm{TiO}_{2}$ by sol-gel method, which could reduce the crystallite size and increase the specific surface area of the catalysts. They investigated the effects of different parameters such as $\mathrm{pH}$ of the solution, amount of catalyst, additives, and kinetics. At $2.5 \mathrm{wt} \%$ sulfate loading, the average percentage of degradation of methyl orange was nearly two times than that of neat $\mathrm{TiO}_{2}$. This material showed photocatalytic activity of $61 \%$ of MO degradation under solar radiation against $12 \%$ of adsorption in the dark. The effect of vanadium ions on the photocatalytic activity of $\mathrm{TiO}_{2}$ nanocrystals, prepared by sol-gel method was investigated using MB by Doong et al. [207]. BET-BJH analysis clearly showed that the fabricated $\mathrm{V}$-doped $\mathrm{TiO}_{2}$ was mesoporous, with high specific surface area. The specific surface areas of $\mathrm{V}$-doped mesoporous $\mathrm{TiO}_{2}$ nanoparticles increased from $88 \pm 2$ to $93 \pm 19 \mathrm{~m}^{2} / \mathrm{g}$ when V/Ti ratios increased from 0.5 to $1.0 \mathrm{wt} \%$. A further increase in the $\mathrm{V} / \mathrm{Ti}$ ratio to $2.0 \mathrm{wt} \%$ reduced the specific surface area of $\mathrm{V}$-doped $\mathrm{TiO}_{2}$ slightly to $86 \pm 9 \mathrm{~m}^{2} / \mathrm{g}$. It was observed that anatase is the main crystalline phase of $\mathrm{V}$-doped mesoporous $\mathrm{TiO}_{2}$, at a calcination temperature of $500^{\circ} \mathrm{C}$. The photodegradation efficiency of $\mathrm{MB}$ by $\mathrm{V} / \mathrm{TiO}_{2}$ was increased under visible light and was consistent with surface area analysis [208].

5.2. Hydrothermal Method. Hydrothermal method is often the method of choice because of its various advantages like cost-effectiveness, low energy consumption, mild reaction condition, and simple equipment requirements. The particle 
properties such as morphology and size can be controlled via the hydrothermal process by adjusting the reaction temperature, time, and concentration of precursors. It is a low-temperature technology thus can save energy and is environmentally benign, because the reactions take place in closed-system conditions using water as the reaction medium. This method is very versatile for the synthesis of nanophase materials and has been well established.

Shen et al. [209] presented Cetyltrimethylam-moniumbromide-(CTAB-) assisted hydrothermally synthesized $\mathrm{ZnIn}_{2} \mathrm{~S}_{4}$ as an efficient visible light driven photocatalyst for hydrogen production. They studied the effects of hydrothermal treatment time and influence of surfactant, CTAB, on the crystal structures, morphologies, and optical properties of $\mathrm{ZnIn}_{2} \mathrm{~S}_{4}$ and the activity was evaluated by photocatalytic hydrogen production from water under visible light irradiation. It was found that the photocatalytic activities of these $\mathrm{ZnIn}_{2} \mathrm{~S}_{4}$ products decreased with the hydrothermal treatment time period while increased with the amount of CTAB. C-doped $\mathrm{Zn}_{3}(\mathrm{OH})_{2} \mathrm{~V}_{2} \mathrm{O}_{7}$ has been prepared by hydrothermal method, in the presence of polyethylene glycol and ethylenediamine tetracetic acid, and used for the degradation of $\mathrm{MB}$. The catalyst exhibited high photocatalytic performance with $90.3 \% \mathrm{MB}$ decolorization after 30 min, much better than the $\mathrm{ZnO}$ photocatalyst (34.6\%), and the TOC removal rate of the solution reached $71.9 \%$ within $30 \mathrm{~min}$ [210]. Zn-doped CdSe prepared by a simple hydrothermal method exhibited high visible light driven activity [211]. Many researchers studied the effect of $\mathrm{Zn}$ in the visible light driven photoactivity of catalysts prepared by hydrothermal method. Photocatalytic decomposition of acetaldehyde was achieved by iron hydroxide $(\mathrm{FeOOH})$ particles, prepared by a hydrothermal method, under visible light [212]. Wu et al. studied the effect of the hydrothermal treatment temperature on the preparation of visible light active $\mathrm{TiO}_{2}$ photocatalyst. The photocatalyst, treated at $160^{\circ} \mathrm{C}$ achieved much more absorption in the visible light compared to $\mathrm{N}-\mathrm{TiO}_{2}$ prepared at $120^{\circ} \mathrm{C}$ and $140^{\circ} \mathrm{C}$ [213]. Jing et al. [214] prepared decahedral $\mathrm{Cu}_{2} \mathrm{WS}_{4}$, by a facile hydrothermal method and employed it as a photocatalyst for photocatalytic hydrogen production for the first time. The hydrothermal method avoided the traditional use of $\mathrm{H}_{2} \mathrm{~S}$ for the preparation of such chalcogenide, which guarantees an environmental friendly process. $\mathrm{Cu}_{2} \mathrm{WS}_{4}$ synthesized at $200^{\circ} \mathrm{C}$ for $72 \mathrm{~h}$ showed the highest activity with the apparent quantum yield of $11 \%$ at $425 \mathrm{~nm}$. Qi Xiao et al. [215] prepared a novel $(\mathrm{C}, \mathrm{S}, \mathrm{Sm})$-tridoped $\mathrm{TiO}_{2}$ photocatalyst by one-step hydrothermal method, and the photocatalytic degradation of potassium ethyl xanthate (KEX) was carried out under visible light irradiation. It was found that the order of photocatalytic activity of $\mathrm{C}-\mathrm{S}-\mathrm{xSm}-\mathrm{TiO}_{2}$ (x represents the $\mathrm{mol} \%$ of $\mathrm{Sm}$ ) samples was dependant on the mol\% of Sm and followed the order $1.0>0.5>1.5>0 \mathrm{~mol} \%$. Ho et al. [216] showed that the S-doped $\mathrm{TiO}_{2}$ prepared by this hydrothermal approach resulted on photodegradation of 4-chlorophenol under visible light irradiation, with much higher photocatalytic activity ( $86 \%$ degradation in $6 \mathrm{~h}$ ) than that obtained by the traditional high temperature $(66 \%$ of the 4-chlorophenol in $6 \mathrm{~h}$ ) thermal annealing method. The photocatalytic activity of $\mathrm{Bi}_{2} \mathrm{WO}_{6}$ powder prepared by a simple hydrothermal method at $150^{\circ} \mathrm{C}$ for $24 \mathrm{~h}$ was evaluated [217] using the photocatalytic oxidation of formaldehyde at room temperature, under visible light irradiation. At $500^{\circ} \mathrm{C}$, $\mathrm{Bi}_{2} \mathrm{WO}_{6}$ powder photocatalyst showed the highest visible light photocatalytic activity due to the good crystallization of the samples.

5.3. Chemical Vapour Deposition. Metal organic chemical vapour deposition (MOCVD) is an interesting and promising method to prepare supported photocatalytic $\mathrm{TiO}_{2}$ films. It is an industrial process applicable to large area deposition. High-quality $\mathrm{TiO}_{2}$ films can be easily and cheaply anchored on various substrates, even bearing the complicated shapes. This method eliminated steps such as saturation, aging, drying, and reduction of any subtle change which critically affect the performance of the catalyst in traditional methods for supported catalysts preparation. This technique has superior adhesion, durability, and uniformity than the corresponding physical vapour deposition (PVD) counterpart [218]. Yoshinaga et al. [219] have proposed a novel technique, chemicalvapor-reductive deposition, for the deposition of metallic nickel nanoparticle onto $\mathrm{TiO}_{2}$ thin film, which was used for photocatalytic hydrogen evolution by the decomposition of ethanol under visible light. For the effective immobilization of $\mathrm{TiO}_{2}$ particles, and to improve the catalytic activity under visible light, Zhang and Lei [153] had prepared $\mathrm{Fe}_{2} \mathrm{O}_{3}-$ $\mathrm{TiO}_{2}$ coatings supported on activated carbon fiber (ACF), in one step by MOCVD. A maximum catalytic efficiency was reached when the loading of $\mathrm{TiO}_{2}$ was $13.7 \mathrm{wt} \%$, and it could be reused without decrease in the catalytic activity. $\mathrm{Fe}-\mathrm{TiO}_{2}$ coatings, supported on activated carbon were developed through a codeposition process of MOCVD method in one step, and were used for the effective degradation of methyl orange under visible light by Zhang et al. [86]. Akhavan et al. [220] synthesized $\mathrm{TiO}_{2} /$ multiwall carbon nanotube (MWNT) heterojunction arrays and immobilized on Si for photoinactivation of E. coli in visible light irradiation. The vertically aligned MWNT arrays were grown on $\sim 5 \mathrm{~nm} \mathrm{Ni}$ thin film deposited over Si by using plasma-enhanced chemical vapor deposition at $650^{\circ} \mathrm{C}$. The MWNTs were coated by $\mathrm{TiO}_{2}$ using dip-coating sol-gel method. The order of visible light-induced photoinactivation of the bacteria was MWNTs $<\mathrm{TiO}_{2}<\mathrm{TiO}_{2} / \mathrm{MWNT}$. Kafizas et al. [221] described the combinatorial atmospheric pressure chemical vapour deposition (cAPCVD) synthesis of anatase $\mathrm{TiO}_{2}$ thin-film with gradating nitrogen dopant. A single film with significant variations in thickness, phase, and composition has been achieved by this method. Transition from predominantly $\mathrm{N}_{s}$-doped, to $\mathrm{N}_{s} / \mathrm{N}_{i}$ mixtures, to purely $\mathrm{N}_{i}$-doped $\mathrm{TiO}_{2}$ was observed by X-ray photoelectron spectroscopy analysis, and the photocatalytic activity was confirmed using stearic acid.

In addition to the advanced methods described, the conventional methods of impregnation, coprecipitation, and so forth was also widely engaged in photocatalyst preparation. The supplementary advantage of specific preparation methods is the development of nanosized metal oxides with uniform pore structure and well defined crystal structure which has pronounced influence in its visible light activity. 


\section{Conclusions}

The use of visible light responsive photocatalysts are found to be a suitable method for degrading harmful organic pollutants and also it can provide a way for the production of energy, and can thus, help to solve many urgent environmental issues faced by mankind today. $\mathrm{TiO}_{2}$ is the most widely studied photocatalyst where visible light activity is achieved mainly by nonmetal doping. A combination of metal as well as nonmetal incorporation prevents electron hole-pair recombination in addition to the extended visible light response. Among the other suitable visible light active photocatalysts, $\mathrm{ZnO}$ based systems are found to be a better choice than that of modified $\mathrm{TiO}_{2}$ photocatalysts, owing to its low-price, very simple synthesis process, biocompatibility nature, high stability, high activity towards photo-induced redox reactions and photocatalytic reducing power for the eradication of environmental pollutants. Photoactivity depends on the synthetic method adapted. Among the various methods, sol gel, hydrothermal and chemical vapour deposition had resulted in highly crystalline and porous catalysts with improved surface area and better activity.

\section{Acknowledgment}

The authors acknowledge the UKM, Grant no. UKM-RF-06FRGS010-2010, for providing assistance.

\section{References}

[1] S. Svanberg, Atomic and Molecular Spectoscopy: Basic Aspects and Practical Applications, Springer-Verlag Berlin Heidelberg, Germany, 2004.

[2] T. Takata, G. Hitoki, J. N. Kondo, M. Hara, H. Kobayashi, and K. Domen, "Visible-light-driven photocatalytic behavior of tantalum-oxynitride and nitride," Research on Chemical Intermediates, vol. 33, no. 1-2, pp. 13-25, 2007.

[3] B. Bandapani, N. J. C. Packham, and J. O. Bockris, in Hydrogen Energy Progress, V. T. Veziroglu, Ed., Pergamon, Oxford, UK, 1984.

[4] S. V. Tambwekar and M. Subrahmanyam, "Photocatalytic generation of hydrogen from hydrogen sulfide: an energy bargain," International Journal of Hydrogen Energy, vol. 22, no. 10-11, pp. 959-965, 1997.

[5] K. G. Kanade, B. B. Kale, J. O. Baeg et al., "Self-assembled aligned $\mathrm{Cu}$ doped $\mathrm{ZnO}$ nanoparticles for photocatalytic hydrogen production under visible light irradiation," Materials Chemistry and Physics, vol. 102, no. 1, pp. 98-104, 2007.

[6] A. Kudo, H. Kato, and I. Tsuji, "Strategies for the development of visible-light-driven photocatalysts for water splitting," Chemistry Letters, vol. 33, no. 12, pp. 1534-1539, 2004.

[7] J. S. Lee, "Photocatalytic water splitting under visible light with particulate semiconductor catalysts," Catalysis Surveys from Asia, vol. 9, no. 4, pp. 217-227, 2005.

[8] R. Abe, K. Sayama, and H. Sugihara, "Development of new photocatalytic water splitting into $\mathrm{H}_{2}$ and $\mathrm{O}_{2}$ using two different semiconductor photocatalysts and a shuttle redox mediator $\mathrm{IO}^{3-} / \mathrm{I}^{-}$, , Journal of Physical Chemistry B, vol. 109, no. 33, pp. 16052-16061, 2005.

[9] K. Maeda and K. Domen, "New non-oxide photocatalysts designed for overall water splitting under visible light,"
Journal of Physical Chemistry C, vol. 111, no. 22, pp. 78517861, 2007.

[10] A. Fujishima and K. Honda, "Electrochemical photolysis of water at a semiconductor electrode," Nature, vol. 238, no. 5358, pp. 37-38, 1972.

[11] M. R. Hoffmann, S. T. Martin, W. Choi, and D. W. Bahnemann, "Environmental applications of semiconductor photocatalysis," Chemical Reviews, vol. 95, no. 1, pp. 69-96, 1995.

[12] S. Chakrabarti and B. K. Dutta, "Photocatalytic degradation of model textile dyes in wastewater using $\mathrm{ZnO}$ as semiconductor catalyst," Journal of Hazardous Materials, vol. 112, no. 3, pp. 269-278, 2004.

[13] M. Vautier, C. Guillard, and J. M. Herrmann, "Photocatalytic degradation of dyes in water: case study of indigo and of indigo carmine," Journal of Catalysis, vol. 201, no. 1, pp. 4659, 2001.

[14] A. B. dos Santos, F. J. Cervantes, and J. B. van Lier, "Review paper on current technologies for decolourisation of textile wastewaters: perspectives for anaerobic biotechnology," Bioresource Technology, vol. 98, no. 12, pp. 2369-2385, 2007.

[15] C. Guillard, H. Lachheb, A. Houas, M. Ksibi, E. Elaloui, and J. M. Herrmann, "Influence of chemical structure of dyes, of $\mathrm{pH}$ and of inorganic salts on their photocatalytic degradation by $\mathrm{TiO}_{2}$ comparison of the efficiency of powder and supported $\mathrm{TiO}_{2}$," Journal of Photochemistry and Photobiology A, vol. 158, no. 1, pp. 27-36, 2003.

[16] P. R. Gogate and A. B. Pandit, "A review of imperative technologies for wastewater treatment I: oxidation technologies at ambient conditions," Advances in Environmental Research, vol. 8, no. 3-4, pp. 501-551, 2004.

[17] T. Sato, Y. Yamamoto, Y. Fujishiro, and S. Uchida, "Intercalation of iron oxide in layered $\mathrm{H}_{2} \mathrm{Ti}_{4} \mathrm{O}_{9}$ and $\mathrm{H}_{4} \mathrm{Nb}_{6} \mathrm{O}_{17}$ : visible-light induced photocatalytic properties," Journal of the Chemical Society, vol. 92, no. 24, pp. 5089-5092, 1996.

[18] J. H. Choy, H. C. Lee, H. Jung, and S. J. Hwang, "A novel synthetic route to $\mathrm{TiO}_{2}$-pillared layered titanate with enhanced photocatalytic activity," Journal of Materials Chemistry, vol. 11, no. 9, pp. 2232-2234, 2001.

[19] W. Choi, A. Termin, and M. R. Hoffmann, "The role of metal ion dopants in quantum-sized $\mathrm{TiO}_{2}$ : correlation between photoreactivity and charge carrier recombination dynamics," Journal of Physical Chemistry, vol. 98, no. 51, pp. 1366913679, 1994.

[20] Z. Zou, J. Ye, K. Sayama, and H. Arakawa, "Direct splitting of water under visible light irradiation with an oxide semiconductor photocatalyst," Nature, vol. 414, no. 6864, pp. 625627, 2001.

[21] R. Asahi, T. Morikawa, T. Ohwaki, K. Aoki, and Y. Taga, "Visible-light photocatalysis in nitrogen-doped titanium oxides," Science, vol. 293, no. 5528, pp. 269-271, 2001.

[22] M. M. Joshi, N. K. Labhsetwar, P. A. Mangrulkar, S. N. Tijare, S. P. Kamble, and S. S. Rayalu, "Visible light induced photoreduction of methyl orange by $\mathrm{N}$-doped mesoporous titania," Applied Catalysis A, vol. 357, no. 1, pp. 26-33, 2009.

[23] K. N. Rao and S. Mohan, "Optical properties of electron; beam evaporated $\mathrm{TiO}_{2}$ films deposited in an ionized oxygen medium," Journal of Vacuum Science and Technology A, vol. 8, no. 8, pp. 3260-3264, 1990.

[24] E. M. Rockafellow, L. K. Stewart, and W. S. Jenks, "Is sulfurdoped $\mathrm{TiO}_{2}$ an effective visible light photocatalyst for remediation?" Applied Catalysis B, vol. 91, no. 1-2, pp. 554-562, 2009. 
[25] N. N. Binitha, Z. Yaakob, and R. Resmi, "Influence of synthesis methods on zirconium doped titania photocatalysts," Central European Journal of Chemistry, vol. 8, no. 1, pp. 182$187,2010$.

[26] S. Yin, H. Hasegawa, D. Maeda, M. Ishitsuka, and T. Sato, "Synthesis of visible-light-active nanosize rutile titania photocatalyst by low temperature dissolution-reprecipitation process," Journal of Photochemistry and Photobiology A, vol. 163, no. 1-2, pp. 1-8, 2004.

[27] J. Lin and J. C. Yu, "An investigation on photocatalytic activities of mixed $\mathrm{TiO}_{2}$-rare earth oxides for the oxidation of acetone in air," Journal of Photochemistry and Photobiology A, vol. 116, no. 1, pp. 63-67, 1998.

[28] S. U. M. Khan, M. Al-Shahry, and W. B. Ingler Jr., "Efficient photochemical water splitting by a chemically modified n$\mathrm{TiO}_{2}$," Science, vol. 297, no. 5590, pp. 2243-2245, 2002.

[29] T. Ohno, M. Akiyoshi, T. Umebayashi, K. Asai, T. Mitsui, and M. Matsumura, "Preparation of S-doped $\mathrm{TiO}_{2}$ photocatalysts and their photocatalytic activities under visible light," Applied Catalysis A, vol. 265, no. 1, pp. 115-121, 2004.

[30] X. Z. Shen, J. Guo, Z. C. Liu, and S. M. Xie, "Visible-lightdriven titania photocatalyst co-doped with nitrogen and ferrum," Applied Surface Science, vol. 254, no. 15, pp. 4726 4731, 2008.

[31] A. W. Xu, Y. Gao, and H. Q. Liu, "The preparation, characterization, and their photocatalytic activities of rareearth-doped $\mathrm{TiO}_{2}$ nanoparticles," Journal of Catalysis, vol. 207, no. 2, pp. 151-157, 2002.

[32] U. Siemon, D. Bahnemann, J. J. Testa, D. Rodríguez, M. I. Litter, and N. Bruno, "Heterogeneous photocatalytic reactions comparing $\mathrm{TiO}_{2}$ and $\mathrm{Pt} / \mathrm{TiO}_{2}$," Journal of Photochemistry and Photobiology A, vol. 148, no. 1-3, pp. 247-255, 2002.

[33] K. Wilke and H. D. Breuer, "The influence of transition metal doping on the physical and photocatalytic properties of titania," Journal of Photochemistry and Photobiology A, vol. 121, no. 1, pp. 49-53, 1999.

[34] A. Zielińska-Jurek, E. Kowalska, J. W. Sobczak, W. Lisowski, B. Ohtani, and A. Zaleska, "Preparation and characterization of monometallic $(\mathrm{Au})$ and bimetallic $(\mathrm{Ag} / \mathrm{Au})$ modifiedtitania photocatalysts activated by visible light," Applied Catalysis B, vol. 101, no. 3-4, pp. 504-514, 2011.

[35] D. Dvoranová, V. Brezová, M. Mazúr, and M. A. Malati, "Investigations of metal-doped titanium dioxide photocatalysts," Applied Catalysis B, vol. 37, no. 2, pp. 91-105, 2002.

[36] X. Z. Li and F. B. Li, "Study of $\mathrm{Au} / \mathrm{Au}^{3+}-\mathrm{TiO}_{2}$ photocatalysts toward visible photooxidation for water and wastewater treatment," Environmental Science and Technology, vol. 35, no. 11, pp. 2381-2387, 2001.

[37] S. Kim, S. J. Hwang, and W. Choi, "Visible light active platinum-ion-doped $\mathrm{TiO}_{2}$ photocatalyst," Journal of Physical Chemistry B, vol. 109, no. 51, pp. 24260-24267, 2005.

[38] Y. Zhang, H. Xu, Y. Xu, H. Zhang, and Y. Wang, "The effect of lanthanide on the degradation of $\mathrm{RB}$ in nanocrystalline $\mathrm{Ln} / \mathrm{TiO}_{2}$ aqueous solution," Journal of Photochemistry and Photobiology A, vol. 170, no. 3, pp. 279-285, 2005.

[39] F. B. Li, X. Z. Li, and M. F. Hou, "Photocatalytic degradation of 2-mercaptobenzothiazole in aqueous $\mathrm{La}^{3+}-\mathrm{TiO}_{2}$ suspension for odor control," Applied Catalysis B, vol. 48, no. 3, pp. 185-194, 2004.

[40] M. Zalas and M. Laniecki, "Photocatalytic hydrogen generation over lanthanides-doped titania," Solar Energy Materials and Solar Cells, vol. 89, no. 2-3, pp. 287-296, 2005.

[41] Y. Wang, H. Cheng, L. Zhang et al., "The preparation, characterization, photoelectrochemical and photocatalytic properties of lanthanide metal-ion-doped $\mathrm{TiO}_{2}$ nanoparticles," Journal of Molecular Catalysis A, vol. 151, no. 1-2, pp. 205-216, 2000.

[42] Y. Xie and C. Yuan, "Visible-light responsive cerium ion modified titania sol and nanocrystallites for $\mathrm{X}-3 \mathrm{~B}$ dye photodegradation," Applied Catalysis B, vol. 46, no. 2, pp. 251-259, 2003.

[43] M. Anpo, "Preparation, characterization, and reactivities of highly functional titanium oxide-based photocatalysts able to operate under UV-visible light irradiation: approaches in realizing high efficiency in the use of visible light," Bulletin of the Chemical Society of Japan, vol. 77, no. 8, pp. 1427-1442, 2004.

[44] H. Yamashita, M. Harada, J. Misaka, M. Takeuchi, K. Ikeue, and M. Anpo, "Degradation of propanol diluted in water under visible light irradiation using metal ion-implanted titanium dioxide photocatalysts," Journal of Photochemistry and Photobiology A, vol. 148, no. 1-3, pp. 257-261, 2002.

[45] J. Zhou, M. Takeuchi, A. K. Ray, M. Anpo, and X. S. Zhao, "Enhancement of photocatalytic activity of P25 $\mathrm{TiO}_{2}$ by vanadium-ion implantation under visible light irradiation," Journal of Colloid and Interface Science, vol. 311, no. 2, pp. 497-501, 2007.

[46] M. Bettinelli, V. Dallacasa, D. Falcomer et al., "Photocatalytic activity of $\mathrm{TiO}_{2}$ doped with boron and vanadium," Journal of Hazardous Materials, vol. 146, no. 3, pp. 529-534, 2007.

[47] A. Kubacka, A. Fuerte, A. Martínez-Arias, and M. FernándezGarcía, "Nanosized Ti-V mixed oxides: effect of doping level in the photo-catalytic degradation of toluene using sunlighttype excitation," Applied Catalysis B, vol. 74, no. 1-2, pp. 2633, 2007.

[48] J. Xu, Y. Ao, D. Fu, and C. Yuan, "Synthesis of Gd-doped $\mathrm{TiO}_{2}$ nanoparticles under mild condition and their photocatalytic activity," Colloids and Surfaces A, vol. 334, no. 1-3, pp. 107111, 2009.

[49] S. Kuang, L. Yang, S. Luo, and Q. Cai, "Fabrication, characterization and photoelectrochemical properties of $\mathrm{Fe}_{2} \mathrm{O}_{3}$ modified $\mathrm{TiO}_{2}$ nanotube arrays," Applied Surface Science, vol. 255, no. 16, pp. 7385-7388, 2009.

[50] K. Vinodgopal, S. Hotchandani, and P. V. Kamat, "Electrochemically assisted photocatalysis. $\mathrm{TiO}_{2}$ particulate film electrodes for photocatalytic degradation of 4-chlorophenol," Journal of Physical Chemistry, vol. 97, no. 35, pp. 9040-9044, 1993.

[51] H. Irie, Y. Watanabe, and K. Hashimoto, "Nitrogenconcentration dependence on photocatalytic activity of $\mathrm{TiO}_{2-x} \mathrm{~N}_{x}$ powders," Journal of Physical Chemistry B, vol. 107, no. 23, pp. 5483-5486, 2003.

[52] T. H. Xu, C. L. Song, Y. Liu, and G. R. Han, "Band structures of $\mathrm{TiO}_{2}$ doped with $\mathrm{N}, \mathrm{C}$ and B," Journal of Zhejiang University, vol. 7, no. 4, pp. 299-303, 2006.

[53] D. Li, H. Haneda, N. K. Labhsetwar, S. Hishita, and N. Ohashi, "Visible-light-driven photocatalysis on fluorinedoped $\mathrm{TiO}_{2}$ powders by the creation of surface oxygen vacancies," Chemical Physics Letters, vol. 401, no. 4-6, pp. 579-584, 2005.

[54] D. Li, H. Haneda, S. Hishita, N. Ohashi, and N. K. Labhsetwar, "Fluorine-doped $\mathrm{TiO}_{2}$ powders prepared by spray pyrolysis and their improved photocatalytic activity for decomposition of gas-phase acetaldehyde," Journal of Fluorine Chemistry, vol. 126, no. 1, pp. 69-77, 2005.

[55] M. Zhou, J. Yu, S. Liu, P. Zhai, and B. Huang, "Sprayhydrolytic synthesis of highly photoactive mesoporous anatase nanospheres for the photocatalytic degradation of 
toluene in air," Applied Catalysis B, vol. 89, no. 1-2, pp. 160166, 2009.

[56] S. Sakthivel and H. Kisch, "Photocatalytic and photoelectrochemical properties of nitrogen-doped titanium dioxide," ChemPhysChem, vol. 4, no. 5, pp. 487-490, 2003.

[57] S. Yin, H. Yamaki, Q. Zhang et al., "Mechanochemical synthesis of nitrogen-doped titania and its visible light induced $\mathrm{NO}_{x}$ destruction ability," Solid State Ionics, vol. 172, no. 1-4, pp. 205-209, 2004.

[58] J. Wang, S. Yin, M. Komatsu, Q. Zhang, F. Saito, and T. Sato, "Photo-oxidation properties of nitrogen doped $\mathrm{SrTiO}_{3}$ made by mechanical activation," Applied Catalysis B, vol. 52, no. 1, pp. 11-21, 2004.

[59] T. Lindgren, J. M. Mwabora, E. Avandaño et al., "Photoelectrochemical and optical properties of nitrogen doped titanium dioxide films prepared by reactive DC magnetron sputtering," Journal of Physical Chemistry B, vol. 107, no. 24, pp. 5709-5716, 2003.

[60] A. Mills, J. Wang, M. Crow, G. Taglioni, and L. Novella, "Novel low-temperature photocatalytic titania films produced by plasma-assisted reactive dc magnetron sputtering," Journal of Photochemistry and Photobiology A, vol. 187, no. 2-3, pp. 370-376, 2007.

[61] S. Sato, "Photocatalytic activity of $\mathrm{NO}_{x}$-doped $\mathrm{TiO}_{2}$ in the visible light region," Chemical Physics Letters, vol. 123, no. 12, pp. 126-128, 1986.

[62] P. W. Chou, S. Treschev, P. H. Chung et al., "Observation of carbon-containing nanostructured mixed titania phases for visible-light photocatalysts," Applied Physics Letters, vol. 89, no. 13, Article ID 131919, 3 pages, 2006.

[63] M. S. Wong, S. H. Wang, T. K. Chen, C. W. Weng, and K. K. Rao, "Co-sputtered carbon-incorporated titanium oxide films as visible light-induced photocatalysts," Surface and Coatings Technology, vol. 202, no. 4-7, pp. 890-894, 2007.

[64] J. H. Park, S. Kim, and A. J. Bard, "Novel carbon-doped $\mathrm{TiO}_{2}$ nanotube arrays with high aspect ratios for efficient solar water splitting," Nano Letters, vol. 6, no. 1, pp. 24-28, 2006.

[65] M. S. Wong, S. W. Hsu, K. K. Rao, and C. P. Kumar, "Influence of crystallinity and carbon content on visible light photocatalysis of carbon doped titania thin films," Journal of Molecular Catalysis A, vol. 279, no. 1, pp. 20-26, 2008.

[66] Y. Aita, M. Komatsu, S. Yin, and T. Sato, "Phasecompositional control and visible light photocatalytic activity of nitrogen-doped titania via solvothermal process," Journal of Solid State Chemistry, vol. 177, no. 9, pp. 3235-3238, 2004.

[67] C. Di Valentin, G. Pacchioni, and A. Selloni, "Theory of carbon doping of titanium dioxide," Chemistry of Materials, vol. 17, no. 26, pp. 6656-6665, 2005.

[68] F. Peng, L. Cai, H. Yu, H. Wang, and J. Yang, "Synthesis and characterization of substitutional and interstitial nitrogendoped titanium dioxides with visible light photocatalytic activity," Journal of Solid State Chemistry, vol. 181, no. 1, pp. 130-136, 2008.

[69] M. Mrowetz, W. Balcerski, A. J. Colussi, and M. R. Hoffmann, "Oxidative power of nitrogen-doped $\mathrm{TiO}_{2}$ photocatalysts under visible illumination," Journal of Physical Chemistry B, vol. 108, no. 45, pp. 17269-17273, 2004.

[70] R. Nakamura, T. Tanaka, and Y. Nakato, "Mechanism for visible light responses in anodic photocurrents at N-doped $\mathrm{TiO}_{2}$ film electrodes," Journal of Physical Chemistry B, vol. 108, no. 30, pp. 10617-10620, 2004.
[71] C. Burda, Y. Lou, X. Chen, A. C. S. Samia, J. Stout, and J. L. Gole, "Enhanced nitrogen doping in $\mathrm{TiO}_{2}$ nanoparticles," Nano Letters, vol. 3, no. 8, pp. 1049-1051, 2003.

[72] H. Wang and J. P. Lewis, "Second-generation photocatalytic materials: anion-doped $\mathrm{TiO}_{2}$," Journal of Physics Condensed Matter, vol. 18, no. 2, pp. 421-434, 2006.

[73] H. L. Qin, G. B. Gu, and S. Liu, "Preparation of nitrogendoped titania with visible-light activity and its application," Comptes Rendus Chimie, vol. 11, no. 1-2, pp. 95-100, 2008.

[74] C. H. Shin, G. Bugli, and G. Djega-Mariadassou, "Preparation and characterization of titanium oxynitrides with high specific surface areas," Journal of Solid State Chemistry, vol. 95, no. 1, pp. 145-155, 1991.

[75] D. Li, H. Haneda, S. Hishita, and N. Ohashi, "Visiblelight-driven nitrogen-doped $\mathrm{TiO}_{2}$ photocatalysts: effect of nitrogen precursors on their photocatalysis for decomposition of gas-phase organic pollutants," Materials Science and Engineering B, vol. 117, no. 1, pp. 67-75, 2005.

[76] C. Belver, R. Bellod, S. J. Stewart, F. G. Requejo, and M. Fernández-García, "Nitrogen-containing $\mathrm{TiO}_{2}$ photocatalysts. Part 2. Photocatalytic behavior under sunlight excitation," Applied Catalysis B, vol. 65, no. 3-4, pp. 309-314, 2006.

[77] Y. Q. Wang, X. J. Yu, and D. Z. Sun, "Synthesis, characterization, and photocatalytic activity of $\mathrm{TiO}_{2-x} \mathrm{~N}_{x}$ nanocatalyst," Journal of Hazardous Materials, vol. 144, no. 1-2, pp. 328333, 2007.

[78] Y. Chen, S. Zhang, Y. Yu et al., "Synthesis, characterization, and photocatalytic activity of N-Doped $\mathrm{TiO}_{2}$ nanotubes," Journal of Dispersion Science and Technology, vol. 29, no. 2, pp. 245-249, 2008.

[79] S. H. Wang, T. K. Chen, K. K. Rao, and M. S. Wong, "Nanocolumnar titania thin films uniquely incorporated with carbon for visible light photocatalysis," Applied Catalysis $B$, vol. 76, no. 3-4, pp. 328-334, 2007.

[80] Y. Sakatani, H. Ando, K. Okusako et al., "Metal ion and N co-doped $\mathrm{TiO}_{2}$ as a visible-light photocatalyst," Journal of Materials Research, vol. 19, no. 7, pp. 2100-2108, 2004.

[81] Y. Sakatani, J. Nunoshige, H. Ando et al., "Photocatalytic Decomposition of Acetaldehyde under Visible Light Irradiation over $\mathrm{La}^{3+}$ and $\mathrm{N} \mathrm{Co-doped} \mathrm{TiO}_{2}$," Chemistry Letters, vol. 32, no. 12, pp. 1156-1157, 2003.

[82] W. Zhao, W. Ma, C. Chen, J. Zhao, and Z. Shuai, "Efficient degradation of toxic organic pollutants with $\mathrm{Ni}_{2} \mathrm{O}_{3} / \mathrm{TiO}_{2-x} \mathrm{~B}_{x}$ under Visible Irradiation," Journal of the American Chemical Society, vol. 126, no. 15, pp. 4782-4783, 2004.

[83] J. W. Shi, J. T. Zheng, Y. Hu, and Y. C. Zhao, "Influence of Fe ${ }^{3+}$ and $\mathrm{Ho}^{3+}$ co-doping on the photocatalytic activity of $\mathrm{TiO}_{2}$," Materials Chemistry and Physics, vol. 106, no. 2-3, pp. 247249, 2007.

[84] D. Li, H. Haneda, S. Hishita, and N. Ohashi, "Visiblelight-driven N-F-codoped $\mathrm{TiO}_{2}$ photocatalysts. 2. Optical characterization, photocatalysis, and potential application to air purification," Chemistry of Materials, vol. 17, no. 10, pp. 2596-2602, 2005.

[85] Z. H. Yuan, J. H. Jia, and L. D. Zhang, "Influence of co-doping of $\mathrm{Zn}(\mathrm{II})+\mathrm{Fe}(\mathrm{III})$ on the photocatalytic activity of $\mathrm{TiO}_{2}$ for phenol degradation," Materials Chemistry and Physics, vol. 73, no. 2-3, pp. 323-326, 2002.

[86] X. Zhang, M. Zhou, and L. Lei, "Co-deposition of photocatalytic Fe doped $\mathrm{TiO}_{2}$ coatings by MOCVD," Catalysis Communications, vol. 7, no. 7, pp. 427-431, 2006. 
[87] V. Balek, D. Li, J. Šubrt et al., "Characterization of nitrogen and fluorine co-doped titania photocatalyst: effect of temperature on microstructure and surface activity properties," Journal of Physics and Chemistry of Solids, vol. 68, no. 5-6, pp. 770-774, 2007.

[88] Q. Ling, J. Sun, Q. Zhou, Q. Zhao, and H. Ren, "Visible-lightdriven boron/ferrum/cerium/titania photocatalyst," Journal of Photochemistry and Photobiology A, vol. 200, no. 2-3, pp. 141-147, 2008.

[89] T. Umebayashi, T. Yamaki, H. Itoh, and K. Asai, "Band gap narrowing of titanium dioxide by sulfur doping," Applied Physics Letters, vol. 81, no. 3, pp. 454-456, 2002.

[90] K. Yang, Y. Dai, and B. Huang, "Origin of the photoactivity in boron-doped anatase and rutile $\mathrm{TiO}_{2}$ calculated from first principles," Physical Review B, vol. 76, no. 19, Article ID 195201, 2007.

[91] P. Silija, Z. Yaakob, M. A. Yarmo, S. Sugunan, and N. N. Binitha, "Visible light active anion codoped sol gel titania photocatalyst for pollutant degradation," Journal of Sol-Gel Science and Technology, vol. 59, no. 2, pp. 252-259, 2011.

[92] N. N. Binitha, Z. Yaakob, P. P. Silija, P. V. Suraja, and S. M. Tasirin, "Effect of Co-doping of nano silver, carbon and nitrogen on titania on the visible light activity for methylorange degradation," Defect and Diffusion Forum, vol. 312-315, pp. 776-781, 2011.

[93] P. S. Yap, T. T. Lim, M. Lim, and M. Srinivasan, "Synthesis and characterization of nitrogen-doped $\mathrm{TiO}_{2} / \mathrm{AC}$ composite for the adsorption-photocatalytic degradation of aqueous bisphenol-A using solar light," Catalysis Today, vol. 151, no. 1-2, pp. 8-13, 2010.

[94] H. Park, W. Choi, and M. R. Hoffmann, "Effects of the preparation method of the ternary $\mathrm{CdS} / \mathrm{TiO}_{2} / \mathrm{Pt}$ hybrid photocatalysts on visible light-induced hydrogen production," Journal of Materials Chemistry, vol. 18, no. 20, pp. 2379-2385, 2008.

[95] L. Ge, M. Xu, and H. Fang, "Photo-catalytic degradation of methyl orange and formaldehyde by $\mathrm{Ag} / \mathrm{InVO}_{4}-\mathrm{TiO}_{2}$ thin films under visible-light irradiation," Journal of Molecular Catalysis A, vol. 258, no. 1-2, pp. 68-76, 2006.

[96] H. Yu, H. Irie, and K. Hashimoto, "Conduction band energy level control of titanium dioxide: toward an efficient visible-light-sensitive photocatalyst," Journal of the American Chemical Society, vol. 132, no. 20, pp. 6898-6899, 2010.

[97] H. Gerischer and M. Lübke, "A particle size effect in the sensitization of $\mathrm{TiO}_{2}$ electrodes by a CdS deposit," Journal of Electroanalytical Chemistry, vol. 204, no. 1-2, pp. 225-227, 1986.

[98] R. Vogel, P. Hoyer, and H. Weller, "Quantum-sized PbS, $\mathrm{CdS}, \mathrm{Ag}_{2} \mathrm{~S}, \mathrm{Sb}_{2} \mathrm{~S}_{3}$, and $\mathrm{Bi}_{2} \mathrm{~S}_{3}$ particles as sensitizers for various nanoporous wide-bandgap semiconductors," Journal of Physical Chemistry, vol. 98, no. 12, pp. 3183-3188, 1994.

[99] A. Kongkanand, K. Tvrdy, K. Takechi, M. Kuno, and P. V. Kamat, "Quantum dot solar cells. Tuning photoresponse through size and shape control of $\mathrm{CdSe}-\mathrm{TiO}_{2}$ architecture," Journal of the American Chemical Society, vol. 130, no. 12, pp. 4007-4015, 2008.

[100] I. Robel, V. Subramanian, M. Kuno, and P. V. Kamat, "Quantum dot solar cells. Harvesting light energy with CdSe nanocrystals molecularly linked to mesoscopic $\mathrm{TiO}_{2}$ films," Journal of the American Chemical Society, vol. 128, no. 7, pp. 2385-2393, 2006.

[101] H. Zhang, S. Ouyang, Z. Li et al., "Preparation, characterization and photocatalytic activity of polycrystalline
$\mathrm{Bi}_{2} \mathrm{O}_{3} / \mathrm{SrTiO}_{3}$ composite powders," Journal of Physics and Chemistry of Solids, vol. 67, no. 12, pp. 2501-2505, 2006.

[102] L. M. Peter, K. G. U. Wijayantha, D. J. Riley, and J. P. Waggett, "Band-edge tuning in self-assembled layers of $\mathrm{Bi}_{2} \mathrm{~S}_{3}$ nanoparticles used to photosensitize nanocrystalline $\mathrm{TiO}_{2}$," Journal of Physical Chemistry B, vol. 107, no. 33, pp. 83788381, 2003.

[103] Y. Bessekhouad, D. Robert, and J. V. Weber, "Photocatalytic activity of $\mathrm{Cu}_{2} \mathrm{O} / \mathrm{TiO}_{2}, \mathrm{Bi}_{2} \mathrm{O}_{3} / \mathrm{TiO}_{2}$ and $\mathrm{ZnMn}_{2} \mathrm{O}_{4} / \mathrm{TiO}_{2}$ heterojunctions," Catalysis Today, vol. 101, no. 3-4, pp. 315321, 2005.

[104] H. Liu, W. Yang, Y. Ma, and J. Yao, "Extended visible light response of binary $\mathrm{TiO}_{2}-\mathrm{Ti}_{2} \mathrm{O}_{3}$ photocatalyst prepared by a photo-assisted sol-gel method," Applied Catalysis A, vol. 299, no. 1-2, pp. 218-223, 2006.

[105] N. Serpone, P. Maruthamuthu, P. Pichat, E. Pelizzetti, and H. Hidaka, "Exploiting the interparticle electron transfer process in the photocatalysed oxidation of phenol, 2chlorophenol and pentachlorophenol: chemical evidence for electron and hole transfer between coupled semiconductors," Journal of Photochemistry and Photobiology, A, vol. 85, no. 3, pp. 247-255, 1995.

[106] C. M. Lieber, "One-dimensional nanostructures: chemistry, physics \& applications," Solid State Communications, vol. 107, no. 11, pp. 607-616, 1998.

[107] H. Yan, R. He, J. Pham, and P. Yang, "Morphogenesis of one-dimensional $\mathrm{ZnO}$ nano- and microcrystals," Advanced Materials, vol. 15, no. 5, pp. 402-405, 2003.

[108] Z. L. Wang, "Splendid one-dimensional nanostructures of zinc oxide: a new nanomaterial family for nanotechnology," ACS Nano, vol. 2, no. 10, pp. 1987-1992, 2008.

[109] Z. L. Wang and J. Song, "Piezoelectric nanogenerators based on zinc oxide nanowire arrays," Science, vol. 312, no. 5771, pp. 242-246, 2006.

[110] C. Reyes, J. Fernández, J. Freer et al., "Degradation and inactivation of tetracycline by $\mathrm{TiO}_{2}$ photocatalysis," Journal of Photochemistry and Photobiology A, vol. 184, no. 1-2, pp. 141-146, 2006.

[111] A. Akyol and M. Bayramoglu, "The degradation of an azo dye in a batch slurry photocatalytic reactor," Chemical Engineering and Processing, vol. 47, no. 12, pp. 2150-2156, 2008.

[112] M. Zhang, T. An, X. Hu, C. Wang, G. Sheng, and J. Fu, "Preparation and photocatalytic properties of a nanometer $\mathrm{ZnO}-\mathrm{SnO}_{2}$ coupled oxide," Applied Catalysis A, vol. 260, no. 2, pp. 215-222, 2004.

[113] A. Umar, M. M. Rahman, S. H. Kim, and Y. B. Hahn, "Zinc oxide nanonail based chemical sensor for hydrazine detection," Chemical Communications, vol. 14, no. 2, pp. 166$168,2008$.

[114] C. Ge, C. Xie, D. Zeng, and S. Cai, "Formaldehyde-, benzene-, and xylene-sensing characterizations of $\mathrm{Zn}-\mathrm{W}-\mathrm{O}$ nanocomposite ceramics," Journal of the American Ceramic Society, vol. 90, no. 10, pp. 3263-3267, 2007.

[115] B. Dindar and S. Içli, "Unusual photoreactivity of zinc oxide irradiated by concentrated sunlight," Journal of Photochemistry and Photobiology A, vol. 140, no. 3, pp. 263-268, 2001.

[116] S. Anandan, N. Ohashi, and M. Miyauchi, "ZnO-based visible-light photocatalyst: band-gap engineering and multielectron reduction by co-catalyst," Applied Catalysis B, vol. 100, no. 3-4, pp. 502-509, 2010.

[117] S. Navarro, J. Fenoll, N. Vela, E. Ruiz, and G. Navarro, "Photocatalytic degradation of eight pesticides in leaching 
water by use of $\mathrm{ZnO}$ under natural sunlight," Journal of Hazardous Materials, vol. 172, no. 2-3, pp. 1303-1310, 2009.

[118] S. Devipriya and S. Yesodharan, "Photocatalytic degradation of pesticide contaminants in water," Solar Energy Materials and Solar Cells, vol. 86, no. 3, pp. 309-348, 2005.

[119] A. A. Aal, S. A. Mahmoud, and A. K. Aboul-Gheit, "Nanocrystalline $\mathrm{ZnO}$ thin film for photocatalytic purification of water," Materials Science and Engineering C, vol. 29, no. 3, pp. 831-835, 2009.

[120] Y. Wang, X. Li, N. Wang, X. Quan, and Y. Chen, "Controllable synthesis of $\mathrm{ZnO}$ nanoflowers and their morphologydependent photocatalytic activities," Separation and Purification Technology, vol. 62, no. 3, pp. 727-732, 2008.

[121] J. Wang, Y. Xie, Z. Zhang et al., "Photocatalytic degradation of organic dyes with $\mathrm{Er}^{3+}: \mathrm{YAlO}_{3} / \mathrm{ZnO}$ composite under solar light," Solar Energy Materials and Solar Cells, vol. 93, no. 3, pp. 355-361, 2009.

[122] C. Karunakaran, P. Gomathisankar, and G. Manikandan, "Preparation and characterization of antimicrobial Cedoped $\mathrm{ZnO}$ nanoparticles for photocatalytic detoxification of cyanide," Materials Chemistry and Physics, vol. 123, no. 2-3, pp. 585-594, 2010.

[123] I. Poulios, A. Avranas, E. Rekliti, and A. Zouboulis, "Photocatalytic oxidation of Auramine $\mathrm{O}$ in the presence of semiconducting oxides," Journal of Chemical Technology and Biotechnology, vol. 75, no. 3, pp. 205-212, 2000.

[124] S. Sakthivel, B. Neppolian, M. Palanichmy, B. Arabindoo, and V. Murugesan, "Photocatlytic degradation of leather dye Acid green 16 using $\mathrm{ZnO}$ in the slurry and thin film forms," Indian Journal of Chemical Technology, vol. 6, no. 1, pp. 161-165, 1999.

[125] K. Maeda, T. Takata, M. Hara et al., "GaN:ZnO solid solution as a photocatalyst for visible-light-driven overall water splitting," Journal of the American Chemical Society, vol. 127, no. 23, pp. 8286-8287, 2005.

[126] X. Qiu, G. Li, X. Sun, L. Li, and X. Fu, "Doping effects of $\mathrm{CO}^{2+}$ ions on $\mathrm{ZnO}$ nanorods and their photocatalytic properties," Nanotechnology, vol. 19, no. 21, Article ID 215703, 2008.

[127] S. S. Shinde, P. S. Shinde, C. H. Bhosale, and K. Y. Rajpure, "Zinc oxide mediated heterogeneous photocatalytic degradation of organic species under solar radiation," Journal of Photochemistry and Photobiology B, vol. 104, no. 3, pp. 425433, 2011.

[128] S. K. Pardeshi and A. B. Patil, "Solar photocatalytic degradation of resorcinol a model endocrine disrupter in water using zinc oxide," Journal of Hazardous Materials, vol. 163, no. 1, pp. 403-409, 2009.

[129] C. Xu, L. Cao, G. Su et al., "Preparation of $\mathrm{ZnO} / \mathrm{Cu}_{2} \mathrm{O}$ compound photocatalyst and application in treating organic dyes," Journal of Hazardous Materials, vol. 176, no. 1-3, pp. 807-813, 2010.

[130] L. C. Chen, Y. J. Tu, Y. S. Wang, R. S. Kan, and C. M. Huang, "Characterization and photoreactivity of N-, S-, and C-doped $\mathrm{ZnO}$ under UV and visible light illumination," Journal of Photochemistry and Photobiology A, vol. 199, no. 2-3, pp. 170-178, 2008.

[131] S. K. Pardeshi and A. B. Patil, "Effect of morphology and crystallite size on solar photocatalytic activity of zinc oxide synthesized by solution free mechanochemical method," Journal of Molecular Catalysis A, vol. 308, no. 1-2, pp. 32-40, 2009.

[132] D. Li and H. Haneda, "Enhancement of photocatalytic activity of sprayed nitrogen-containing $\mathrm{ZnO}$ powders by coupling with metal oxides during the acetaldehyde decomposition," Chemosphere, vol. 54, no. 8, pp. 1099-1110, 2004.

[133] G. Guo and J. Huang, "Preparation of mesoporous tantalum oxide and its enhanced photocatalytic activity," Materials Letters, vol. 65, no. 1, pp. 64-66, 2011.

[134] M. Hara, G. Hitoki, T. Takata, J. N. Kondo, H. Kobayashi, and $\mathrm{K}$. Domen, "TaON and $\mathrm{Ta}_{3} \mathrm{~N}_{5}$ as new visible light driven photocatalysts," Catalysis Today, vol. 78, no. 1-4, pp. 555560, 2003.

[135] C. M. Fang, E. Orhan, G. A. De Wijs et al., "The electronic structure of tantalum (oxy)nitrides $\mathrm{TaON}$ and $\mathrm{Ta}_{3} \mathrm{~N}_{5}$," Journal of Materials Chemistry, vol. 11, no. 4, pp. 1248-1252, 2001.

[136] N. E. Brese, M. O'Keeffe, P. Rauch, and F. J. Disalvo, "Structure of $\mathrm{Ta}_{3} \mathrm{~N}_{5}$ at $16 \mathrm{~K}$ by time-of-flight neutron diffraction," Acta Crystallographica Section C, vol. 47, no. 11, pp. 2291-2294, 1991.

[137] Y. Lee, K. Nukumizu, T. Watanabe et al., "Effect of $10 \mathrm{MPa}$ ammonia treatment on the activity of visible light responsive $\mathrm{Ta}_{3} \mathrm{~N}_{5}$ photocatalyst," Chemistry Letters, vol. 35 , no. 4, pp. 352-353, 2006.

[138] A. Ishikawa, T. Takata, J. N. Kondo, M. Hara, and K. Domen, "Electrochemical behavior of thin $\mathrm{Ta}_{3} \mathrm{~N}_{5}$ semiconductor film," Journal of Physical Chemistry B, vol. 108, no. 30, pp. 11049-11053, 2004.

[139] H. Kato and A. Kudo, "New tantalate photocatalysts for water decomposition into $\mathrm{H}_{2}$ and $\mathrm{O}_{2}$," Chemical Physics Letters, vol. 295, no. 5-6, pp. 487-492, 1998.

[140] K. Maeda, H. Terashima, K. Kase, and K. Domen, "Nanoparticulate precursor route to fine particles of $\mathrm{TaON}$ and $\mathrm{ZrO}_{2}$ $\mathrm{TaON}$ solid solution and their photocatalytic activity for hydrogen evolution under visible light," Applied Catalysis A, vol. 357, no. 2, pp. 206-212, 2009.

[141] S. J. Henderson and A. L. Hector, "Structural and compositional variations in $\mathrm{Ta}_{3} \mathrm{~N}_{5}$ produced by high-temperature ammonolysis of tantalum oxide," Journal of Solid State Chemistry, vol. 179, no. 11, pp. 3518-3524, 2006.

[142] J. Luan, Z. Zou, M. Lu, S. Zheng, and Y. Chen, "Growth, structural and photophysical properties of $\mathrm{Bi}_{2} \mathrm{GaTaO}_{7}$," Journal of Crystal Growth, vol. 273, no. 1-2, pp. 241-247, 2004.

[143] J. Z. Kong, A. D. Li, H. F. Zhai, Y. P. Gong, H. Li, and D. Wu, "Preparation, characterization of the Ta-doped $\mathrm{ZnO}$ nanoparticles and their photocatalytic activity under visiblelight illumination," Journal of Solid State Chemistry, vol. 182, no. 8, pp. 2061-2067, 2009.

[144] G. Zhang, M. Li, S. Yu, S. Zhang, B. Huang, and J. Yu, "Synthesis of nanometer-size $\mathrm{Bi}_{3} \mathrm{TaO}_{7}$ and its visible-light photocatalytic activity for the degradation of a 4BS dye," Journal of Colloid and Interface Science, vol. 345, no. 2, pp. 467-473, 2010.

[145] T. Ishii, H. Kato, and A. Kudo, " $\mathrm{H}_{2}$ evolution from an aqueous methanol solution on $\mathrm{SrTiO}_{3}$ photocatalysts codoped with chromium and tantalum ions under visible light irradiation," Journal of Photochemistry and Photobiology A, vol. 163, no. 1-2, pp. 181-186, 2004.

[146] S. W. Cao and Y. J. Zhu, "Hierarchically nanostructured $\alpha-\mathrm{Fe}_{2} \mathrm{O}_{3}$ hollow spheres: preparation, growth mechanism, photocatalytic property, and application in water treatment," Journal of Physical Chemistry C, vol. 112, no. 16, pp. 62536257, 2008.

[147] A. Kong, H. Wang, J. Li, and Y. Shan, "Preparation of super paramagnetic crystalline mesoporous $\gamma-\mathrm{Fe}_{2} \mathrm{O}_{3}$ with 
high surface," Materials Letters, vol. 62, no. 6-7, pp. 943-945, 2008.

[148] S. W. Cao and Y. J. Zhu, "Surfactant-free preparation and drug release property of magnetic hollow core/shell hierarchical nanostructures," Journal of Physical Chemistry C, vol. 112, no. 32, pp. 12149-12156, 2008.

[149] J. Bandara, U. Klehm, and J. Kiwi, "Raschig rings- $\mathrm{Fe}_{2} \mathrm{O}_{3}$ composite photocatalyst activate in the degradation of 4chlorophenol and orange II under daylight irradiation," Applied Catalysis B, vol. 76, no. 1-2, pp. 73-81, 2007.

[150] J. K. Leland and A. J. Bard, "Photochemistry of colloidal semiconducting iron oxide polymorphs," Journal of Physical Chemistry, vol. 91, no. 19, pp. 5076-5083, 1987.

[151] B. Pala, M. Sharonb, and G. Nogami, "Preparation and characterisation of $\mathrm{TiO}_{2} / \mathrm{Fe}_{2} \mathrm{O}_{3}$ binary mixed oxides and its photocatalytic properties," Materials Chemistry and Physics, vol. 59, no. 3, pp. 254-261, 1999.

[152] X. Zhang, Y. Cao, S. Kan et al., "Study on the photo-induced interfacial charge transfer in $\mathrm{TiO}_{2} / \mathrm{Fe}_{2} \mathrm{O}_{3}$ heterostructured composite film," Thin Solid Films, vol. 327-329, no. 1-2, pp. 568-570, 1998.

[153] X. Zhang and L. Lei, "Preparation of photocatalytic $\mathrm{Fe}_{2} \mathrm{O}_{3}$ $\mathrm{TiO}_{2}$ coatings in one step by metal organic chemical vapor deposition," Applied Surface Science, vol. 254, no. 8, pp. 24062412, 2008.

[154] E. S. Mora, E. G. Barojasb, E. R. Rojas, and R. S. Gonzalez, "Morphological, optical and photocatalytic properties of $\mathrm{TiO}_{2}-\mathrm{Fe}_{2} \mathrm{O}_{3}$ multilayers," Solar Energy Materials and Solar Cells, vol. 91, no. 15-16, pp. 1412-1415, 2007.

[155] O. Akhavan and R. Azimirad, "Photocatalytic property of $\mathrm{Fe}_{2} \mathrm{O}_{3}$ nanograin chains coated by $\mathrm{TiO}_{2}$ nanolayer in visible light irradiation," Applied Catalysis A, vol. 369, no. 1-2, pp. 77-82, 2009.

[156] F. Ye and A. Ohmori, "The photocatalytic activity and photoabsorption of plasma sprayed $\mathrm{TiO}_{2}-\mathrm{Fe}_{3} \mathrm{O}_{4}$ binary oxide coatings," Surface and Coatings Technology, vol. 160, no. 1, pp. 62-67, 2002.

[157] P. Vijayan, C. Mahendiran, C. Suresh, and K. Shanthi, "Photocatalytic activity of iron doped nanocrystalline titania for the oxidative degradation of 2,4,6-trichlorophenol," Catalysis Today, vol. 141, no. 1-2, pp. 220-224, 2009.

[158] R. Khan, S. W. Kim, T. J. Kim, and C. M. Nam, "Comparative study of the photocatalytic performance of boron-iron Co-doped and boron-doped $\mathrm{TiO}_{2}$ nanoparticles," Materials Chemistry and Physics, vol. 112, no. 1, pp. 167-172, 2008.

[159] C. Adán, A. Bahamonde, M. Fernández-García, and A. Martínez-Arias, "Structure and activity of nanosized irondoped anatase $\mathrm{TiO}_{2}$ catalysts for phenol photocatalytic degradation," Applied Catalysis B, vol. 72, no. 1-2, pp. 11-17, 2007.

[160] W. C. Hung, S. H. Fu, J. J. Tseng, H. Chu, and T. H. Ko, "Study on photocatalytic degradation of gaseous dichloromethane using pure and iron ion-doped $\mathrm{TiO}_{2}$ prepared by the sol-gel method," Chemosphere, vol. 66, no. 11, pp. 2142-2151, 2007.

[161] J. A. Navío, G. Colón, M. Macías, C. Real, and M. I. Litter, "Iron-doped titania semiconductor powders prepared by a sol-gel method. Part I: synthesis and characterization," Applied Catalysis A, vol. 177, no. 1, pp. 111-120, 1999.

[162] T. Kawahara, K. I. Yamada, and H. Tada, "Visible light photocatalytic decomposition of 2-naphthol by anodicbiased $\alpha-\mathrm{Fe}_{2} \mathrm{O}_{3}$ film," Journal of Colloid and Interface Science, vol. 294, no. 2, pp. 504-507, 2006.
[163] C. Shifu, Z. Wei, L. Wei, Z. Huaye, Y. Xiaoling, and C. Yinghao, "Preparation, characterization and activity evaluation of p-n junction photocatalyst p- $\mathrm{CaFe}_{2} \mathrm{O}_{4} / \mathrm{n}-\mathrm{Ag}_{3} \mathrm{VO}_{4}$ under visible light irradiation," Journal of Hazardous Materials, vol. 172, no. 2-3, pp. 1415-1423, 2009.

[164] X. Li, Y. Hou, Q. Zhao, W. Teng, X. Hu, and G. Chen, "Capability of novel $\mathrm{ZnFe}_{2} \mathrm{O}_{4}$ nanotube arrays for visiblelight induced degradation of 4-chlorophenol," Chemosphere, vol. 82, no. 4, pp. 581-586, 2011.

[165] H. Liu, H. K. Shon, X. Sun, S. Vigneswaran, and H. Nan, "Preparation and characterization of visible light responsive $\mathrm{Fe}_{2} \mathrm{O}_{3}-\mathrm{TiO}_{2}$ composites," Applied Surface Science, vol. 257, no. 13, pp. 5813-5819, 2011.

[166] Y. R. Smith, K. J. Antony Raj, V. Ravi Subramanian, and B. Viswanathan, "Sulfated $\mathrm{Fe}_{2} \mathrm{O}_{3}-\mathrm{TiO}_{2}$ synthesized from ilmenite ore: a visible light active photocatalyst," Colloids and Surfaces A, vol. 367, no. 1-3, pp. 140-147, 2010.

[167] E. Zintl and L. Varino, "Process for the manufacture of pure bismuth vanadate," German Patent 422947, 1925.

[168] J. Tang, Z. Zou, and J. Ye, "Efficient photocatalytic decomposition of organic contaminants over $\mathrm{CaBi} 2 \mathrm{O} 4$ under visible-light irradiation," Angewandte Chemie-International Edition, vol. 43, no. 34, pp. 4463-4466, 2004.

[169] J. Tang, Z. Zou, and J. Ye, "Effects of substituting $\mathrm{Sr}^{2+}$ and $\mathrm{Ba}^{2+}$ for $\mathrm{Ca}^{2+}$ on the structural properties and photocatalytic behaviors of $\mathrm{CaIn}_{2} \mathrm{O}_{4}$," Chemistry of Materials, vol. 16, no. 9, pp. 1644-1649, 2004.

[170] Y. Sun, C. Wu, R. Long, Y. Cui, S. Zhang, and Y. Xie, "Synthetic loosely packed monoclinic $\mathrm{BiVO}_{4}$ nanoellipsoids with novel multiresponses to visible light, trace gas and temperature," Chemical Communications, no. 30, pp. 45424544, 2009.

[171] J. D. Bierlein and A. W. Sleight, "Ferroelasticity in $\mathrm{BiVO}_{4}$," Solid State Communications, vol. 16, no. 1, pp. 69-70, 1975.

[172] A. R. Lim, S. H. Choh, and M. S. Jang, "Ferroelastic phase transition of $\mathrm{BiVO}_{4}$ studied by $51 \mathrm{~V}$ NMR," Ferroelectrics, vol. 94, pp. 389-394, 1989.

[173] A. Kudo, K. Ueda, H. Kato, and I. Mikami, "Photocatalytic $\mathrm{O}_{2}$ evolution under visible light irradiation on $\mathrm{BiVO}_{4}$ in aqueous $\mathrm{AgNO}_{3}$ solution," Catalysis Letters, vol. 53, no. 3-4, pp. 229-230, 1998.

[174] A. Kudo, K. Omori, and H. Kato, "A novel aqueous process for preparation of crystal form-controlled and highly crystalline $\mathrm{BiVO}_{4}$ powder from layered vanadates at room temperature and its photocatalytic and photophysical properties," Journal of the American Chemical Society, vol. 121, no. 49, pp. 11459-11467, 1999.

[175] K. Sayama, A. Nomura, T. Arai et al., "Photoelectrochemical decomposition of water into $\mathrm{H}_{2}$ and $\mathrm{O}_{2}$ on porous $\mathrm{BiVO}_{4}$ thin-film electrodes under visible light and significant effect of Ag Ion treatment," Journal of Physical Chemistry B, vol. 110, no. 23, pp. 11352-11360, 2006.

[176] I. C. Vinke, J. Diepgrond, B. A. Boukamp, K. J. de Vries, and A. J. Burggraaf, "Bulk and electrochemical properties of BiVO $_{4}$," Solid State Ionics, vol. 57, no. 1-2, pp. 83-89, 1992.

[177] A. Walsh, Y. Yan, M. N. Huda, M. M. Al-Jassim, and S. H. Wei, "Band edge electronic structure of $\mathrm{BiVO}_{4}$ : elucidating the role of the Bi s and V d orbitals," Chemistry of Materials, vol. 21, no. 3, pp. 547-551, 2009.

[178] A. Kudo and S. Hijii, " $\mathrm{H}_{2}$ or $\mathrm{O}_{2}$ evolution from aqueous solutions on layered oxide photocatalysts consisting of $\mathrm{Bi}^{3+}$ with $6 \mathrm{~s}^{2}$ configuration and $\mathrm{d} 0$ transition metal ions," Chemistry Letters, no. 10, pp. 1103-1104, 1999. 
[179] J. Tang, Z. Zou, and J. Ye, "Photocatalytic decomposition of organic contaminants by $\mathrm{Bi}_{2} \mathrm{WO}_{6}$ under visible light irradiation," Catalysis Letters, vol. 92, no. 1-2, pp. 53-56, 2004.

[180] Y. Li, J. Liu, and X. Huang, "Synthesis and visible-light photocatalytic property of $\mathrm{Bi}_{2} \mathrm{WO}_{6}$ hierarchical octahedronlike structures," Nanoscale Research Letters, vol. 3, no. 10, pp. 365-371, 2008.

[181] J. Ye, Z. Zou, H. Arakawa et al., "Correlation of crystal and electronic structures with photophysicalp roperties of water splitting photocatalysts $\mathrm{InMO}_{4}\left(\mathrm{M}=\mathrm{V}^{5+}, \mathrm{Nb}^{5+}, \mathrm{Ta}^{5+}\right)$," Journal Photochemistry Photobiology A, vol. 148, no. 1-3, pp. 79-83, 2002.

[182] Z. Zou, J. Ye, and H. Arakawa, "Structural properties of $\mathrm{InNbO}_{4}$ and $\mathrm{InTaO}_{4}$ : correlation with photocatalytic and photophysical properties," Chemical Physics Letters, vol. 332, no. 3-4, pp. 271-277, 2000.

[183] R. Konta, H. Kato, H. Kobayashi, and A. Kudo, "Photophysical properties and photocatalytic activities under visible light irradiation of silver vanadates," Physical Chemistry Chemical Physics, vol. 5, no. 14, pp. 3061-3065, 2003.

[184] X. Hu and C. Hu, "Preparation and visible-light photocatalytic activity of $\mathrm{Ag}_{3} \mathrm{VO}_{4}$ powders," Journal of Solid State Chemistry, vol. 180, no. 2, pp. 725-732, 2007.

[185] S. Kittaka, S. Nishida, and T. Ohtani, "Mechanochemical reactions between $\mathrm{Ag}_{2} \mathrm{O}$ and $\mathrm{V}_{2} \mathrm{O}_{5}$ to form crystalline silver vanadates," Journal of Solid State Chemistry, vol. 169, no. 1, pp. 139-142, 2002.

[186] T. A. Albrecht, C. L. Stern, and K. R. Poeppelmeier, "The $\mathrm{Ag}_{2} \mathrm{O}-\mathrm{V}_{2} \mathrm{O}_{5}-\mathrm{HF}(\mathrm{aq})$ system and crystal structure of $\alpha$ $\mathrm{Ag}_{3} \mathrm{VO}_{4}$," Inorganic Chemistry, vol. 46, no. 5, pp. 1704-1708, 2007.

[187] X. Hu, C. Hu, and J. Qu, "Preparation and visible-light activity of silver vanadate for the degradation of pollutants," Materials Research Bulletin, vol. 43, no. 11, pp. 2986-2997, 2008.

[188] K. Domen, J. N. Kondo, M. Hara, and T. Takata, "Photo- and mechano-catalytic overall water splitting reactions to form hydrogen and oxygen on heterogeneous catalysts," Bulletin of the Chemical Society of Japan, vol. 73, no. 6, pp. 1307-1331, 2000.

[189] A. Kudo, "Photocatalyst materials for water splitting," Catalysis Surveys from Asia, vol. 7, no. 1, pp. 31-38, 2003.

[190] H. Kato and A. Kudo, "Visible-light-response and photocatalytic activities of $\mathrm{TiO}_{2}$ and $\mathrm{SrTiO}_{3}$ photocatalysts codoped with antimony and chromium," Journal of Physical Chemistry $B$, vol. 106, no. 19, pp. 5029-5034, 2002.

[191] H. Kato, H. Kobayashi, and A. Kudo, "Role of $\mathrm{Ag}^{+}$in the band structures and photocatalytic properties of $\mathrm{AgMO}_{3}$ (M: Ta and $\mathrm{Nb}$ ) with the perovskite structure," Journal of Physical Chemistry B, vol. 106, no. 48, pp. 12441-12447, 2002.

[192] R. Abe, H. Takami, N. Murakami, and B. Ohtani, "Pristine simple oxides as visible light driven photocatalysts: highly efficient decomposition of organic compounds over platinum-loaded tungsten oxide," Journal of the American Chemical Society, vol. 130, no. 25, pp. 7780-7781, 2008.

[193] H. Irie, S. Miura, K. Kamiya, and K. Hashimoto, "Efficient visible light-sensitive photocatalysts: grafting $\mathrm{Cu}(\mathrm{II})$ ions onto $\mathrm{TiO}_{2}$ and $\mathrm{WO}_{3}$ photocatalysts," Chemical Physics Letters, vol. 457, no. 1-3, pp. 202-205, 2008.

[194] T. Arai, M. Horiguchi, M. Yanagida, T. Gunji, H. Sugihara, and K. Sayama, "Complete oxidation of acetaldehyde and toluene over a $\mathrm{Pd} / \mathrm{WO}_{3}$ photocatalyst under fluorescent- or visible-light irradiation," Chemical Communications, no. 43, pp. 5565-5567, 2008.
[195] Y. H. Kim, H. Irie, and K. Hashimoto, "A visible lightsensitive tungsten carbide/tungsten trioxide composite photocatalyst," Applied Physics Letters, vol. 92, no. 18, pp. 182107-182110, 2008.

[196] P. Cheng, C. Deng, M. Gu, and W. Shangguan, "Visible-light responsive zinc ferrite doped titania photocatalyst for methyl orange degradation," Journal of Materials Science, vol. 42, no. 22, pp. 9239-9244, 2007.

[197] L. V. Saraf, S. I. Patil, S. B. Ogale, S. R. Sainkar, and S. T. Kshirsager, "Synthesis of nanophase $\mathrm{TiO}_{2}$ by ion beam sputtering and cold condensation technique," International Journal of Modern Physics B, vol. 12, no. 25, pp. 2635-2647, 1998.

[198] S. G. Hur, T. W. Kim, S. J. Hwang, and J. H. Choy, "Influences of A- and B-site cations on the physicochemical properties of perovskite-structured $\mathrm{A}\left(\mathrm{In}_{1 / 3} \mathrm{Nb}_{1 / 3} \mathrm{~B}_{1 / 3}\right) \mathrm{O}_{3}(\mathrm{~A}=\mathrm{Sr}, \mathrm{Ba}$; $\mathrm{B}=\mathrm{Sn}, \mathrm{Pb})$ photocatalysts," Journal of Photochemistry and Photobiology A, vol. 183, no. 1-2, pp. 176-181, 2006.

[199] H. Y. Lin, Y. F. Chen, and Y. W. Chen, "Water splitting reaction on $\mathrm{NiO} / \mathrm{InVO}_{4}$ under visible light irradiation," International Journal of Hydrogen Energy, vol. 32, no. 1, pp. 86-92, 2007.

[200] A. Kudo and M. Sekizawa, "Photocatalytic $\mathrm{H}_{2}$ evolution under visible light irradiation on $\mathrm{Zn}_{1-x} \mathrm{Cu}_{x} \mathrm{~S}$ solid solution," Catalysis Letters, vol. 58, no. 4, pp. 241-243, 1999.

[201] D. W. Hwang, J. Kim, T. J. Park, and J. S. Lee, "Mg-doped $\mathrm{WO}_{3}$ as a novel photocatalyst for visible light-induced water splitting," Catalysis Letters, vol. 80, no. 1-2, pp. 53-57, 2002.

[202] Z. H. Yuan and L. D. Zhang, "Synthesis, characterization and photocatalytic activity of $\mathrm{ZnFe}_{2} \mathrm{O}_{4} / \mathrm{TiO}_{2}$ nanocomposite," Journal of Materials Chemistry, vol. 11, no. 4, pp. 1265-1268, 2001.

[203] M. A. Valenzuela, P. Bosch, J. Jiménez-Becerrill, O. Quiroz, and A. I. Páez, "Preparation, characterization and photocatalytic activity of $\mathrm{ZnO}, \mathrm{Fe}_{2} \mathrm{O}_{3}$ and $\mathrm{ZnFe}_{2} \mathrm{O}_{4}$," Journal of Photochemistry and Photobiology A, vol. 148, no. 1-3, pp. 177-182, 2002.

[204] S. Senthilkumaar, K. Porkodi, and R. Vidyalakshmi, "Photodegradation of a textile dye catalyzed by sol-gel derived nanocrystalline $\mathrm{TiO}_{2}$ via ultrasonic irradiation," Journal of Photochemistry and Photobiology A, vol. 170, no. 3, pp. 225232, 2005.

[205] Y. S. Jung, D. W. Kim, Y. S. Kim, E. K. Park, and S. H. Baeck, "Synthesis of alumina-titania solid solution by sol-gel method," Journal of Physics and Chemistry of Solids, vol. 69, no. 5-6, pp. 1464-1467, 2008.

[206] K. M. Parida, N. Sahu, N. R. Biswal, B. Naik, and A. C. Pradhan, "Preparation, characterization, and photocatalytic activity of sulfate-modified titania for degradation of methyl orange under visible light," Journal of Colloid and Interface Science, vol. 318, no. 2, pp. 231-237, 2008.

[207] R. A. Doong, P. Y. Chang, and C. H. Huang, "Microstructural and photocatalytic properties of sol-gel-derived vanadiumdoped mesoporous titanium dioxide nanoparticles," Journal of Non-Crystalline Solids, vol. 355, no. 45-47, pp. 2302-2308, 2009.

[208] F. Sayilkan, S. Erdemoğlu, M. Asiltürk et al., "Photocatalytic performance of pure anatase nanocrystallite $\mathrm{TiO}_{2}$ synthesized under low temperature hydrothermal conditions," Materials Research Bulletin, vol. 41, no. 12, pp. 2276-2285, 2006.

[209] S. Shen, L. Zhao, and L. Guo, "Cetyltrimethylammoniumbromide (CTAB)-assisted hydrothermal synthesis of $\mathrm{ZnIn}_{2} \mathrm{~S}_{4}$ as an efficient visible-light-driven photocatalyst for hydrogen 
production," International Journal of Hydrogen Energy, vol. 33, no. 17, pp. 4501-4510, 2008.

[210] H. Guo, J. Chen, W. Weng, and S. Li, "Hydrothermal synthesis of C-doped $\mathrm{Zn}_{3}(\mathrm{OH})_{2} \mathrm{~V}_{2} \mathrm{O}_{7}$ nanorods and their photocatalytic properties under visible light illumination," Applied Surface Science, vol. 257, no. 9, pp. 3920-3923, 2011.

[211] L. Song and S. Zhang, "Hydrothermal synthesis and highly visible light-induced photocatalytic activity of zinc-doped cadmium selenide photocatalysts," Chemical Engineering Journal, vol. 166, no. 2, pp. 779-782, 2011.

[212] N. Murakami, T. Matsuo, T. Tsubota, and T. Ohno, "Photocatalytic reaction over iron hydroxides: a novel visible-lightresponsive photocatalyst," Catalysis Communications, vol. 12, no. 5, pp. 341-344, 2011.

[213] D. Wu, M. Long, W. Cai, C. Chen, and Y. Wu, "Low temperature hydrothermal synthesis of $\mathrm{N}$-doped $\mathrm{TiO}_{2}$ photocatalyst with high visible-light activity," Journal of Alloys and Compounds, vol. 502, no. 2, pp. 289-294, 2010.

[214] D. Jing, M. Liu, Q. Chen, and L. Guo, "Efficient photocatalytic hydrogen production under visible light over a novel W-based ternary chalcogenide photocatalyst prepared by a hydrothermal process," International Journal of Hydrogen Energy, vol. 35, no. 16, pp. 8521-8527, 2010.

[215] Q. Xiao, L. Ouyang, L. Gao, and W. Jiang, "One-step hydrothermal preparation and photocatalytic activity of (C, S, Sm)-tridoped mesoporous $\mathrm{TiO}_{2}$ photocatalyst under visible light irradiation," Materials Chemistry and Physics, vol. 124, no. 2-3, pp. 1210-1215, 2010.

[216] W. Ho, J. C. Yu, and S. Lee, "Low-temperature hydrothermal synthesis of S-doped $\mathrm{TiO}_{2}$ with visible light photocatalytic activity," Journal of Solid State Chemistry, vol. 179, no. 4, pp. 1171-1176, 2006.

[217] J. Yu, J. Xiong, B. Cheng, Y. Yu, and J. Wang, "Hydrothermal preparation and visible-light photocatalytic activity of $\mathrm{Bi}_{2} \mathrm{WO}_{6}$ powders," Journal of Solid State Chemistry, vol. 178, no. 6, pp. 1968-1972, 2005.

[218] A. Mills, G. Hill, S. Bhopal, I. P. Parkin, and S. A. O’Neill, "Thick titanium dioxide films for semiconductor photocatalysis," Journal of Photochemistry and Photobiology A, vol. 160, no. 3, pp. 185-194, 2003.

[219] M. Yoshinaga, K. Yamamoto, N. Sato, K. Aoki, T. Morikawa, and A. Muramatsu, "Remarkably enhanced photocatalytic activity by nickel nanoparticle deposition on sulfur-doped titanium dioxide thin film," Applied Catalysis B, vol. 87, no. 3-4, pp. 239-244, 2009.

[220] O. Akhavan, M. Abdolahad, Y. Abdi, and S. Mohajerzadeh, "Synthesis of titania/carbon nanotube heterojunction arrays for photoinactivation of E. coli in visible light irradiation," Carbon, vol. 47, no. 14, pp. 3280-3287, 2009.

[221] A. Kafizas, C. Crick, and I. P. Parkin, "The combinatorial atmospheric pressure chemical vapour deposition (cAPCVD) of a gradating substitutional/interstitial N-doped anatase $\mathrm{TiO}_{2}$ thin-film; UVA and visible light photocatalytic activities," Journal of Photochemistry and Photobiology A, vol. 216, no. 2-3, pp. 156-166, 2010.

[222] N. Dubey, S. S. Rayalu, N. K. Labhsetwar, and S. Devotta, "Visible light active zeolite-based photocatalysts for hydrogen evolution from water," International Journal of Hydrogen Energy, vol. 33, no. 21, pp. 5958-5966, 2008.

[223] N. Kometani, A. Fujita, and Y. Yonezawa, "Synthesis of Ndoped titanium oxide by hydrothermal treatment," Journal of Materials Science, vol. 43, no. 7, pp. 2492-2498, 2008.

[224] Y. Sun, Y. Xie, C. Wu, S. Zhang, and S. Jiang, "Aqueous synthesis of mesostructured $\mathrm{BiVO}_{4}$ quantum tubes with excellent dual response to visible light and temperature," Nano Research, vol. 3, no. 9, pp. 620-631, 2010.

[225] Y. Yokosuka, K. Oki, H. Nishikiori, Y. Tatsumi, N. Tanaka, and T. Fujii, "Photocatalytic degradation of trichloroethylene using N-doped $\mathrm{TiO}_{2}$ prepared by a simple sol-gel process," Research on Chemical Intermediates, vol. 35, no. 1, pp. 43-53, 2009.

[226] D. F. Li, N. Xu, Y. F. Chen, and Z. G. Zou, "Role of d electrons in oxide semiconductor $\mathrm{CoTa}_{2} \mathrm{O}_{6}$ on photocatalytic and photophysical properties," Research on Chemical Intermediates, vol. 31, no. 4-6, pp. 521-527, 2005.

[227] Z. Wang, W. Luo, S. Yan et al., " $\mathrm{BiVO}_{4}$ nano-leaves: mild synthesis and improved photocatalytic activity for $\mathrm{O}_{2}$ production under visible light irradiation," Crystal Engineering Community, vol. 13, no. 7, pp. 2500-2504, 2011. 


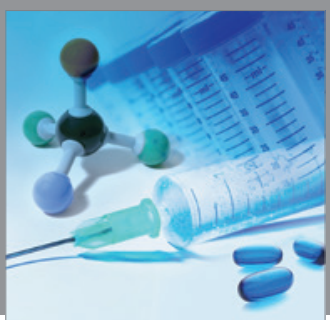

International Journal of

Medicinal Chemistry

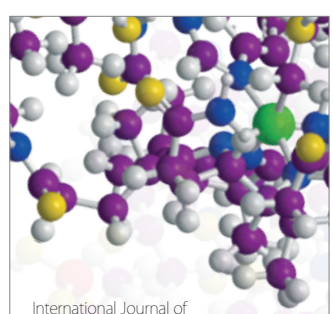

Carbohydrate Chemistry

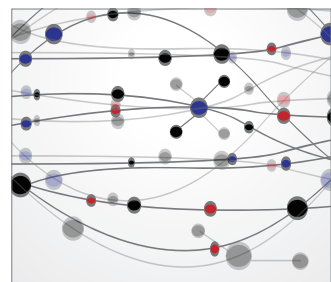

The Scientific World Journal
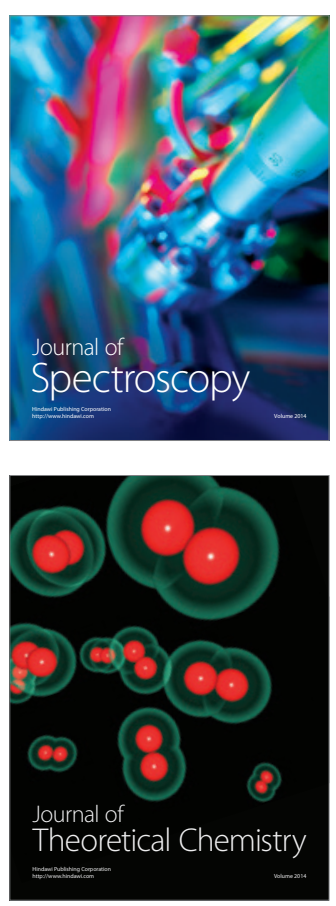
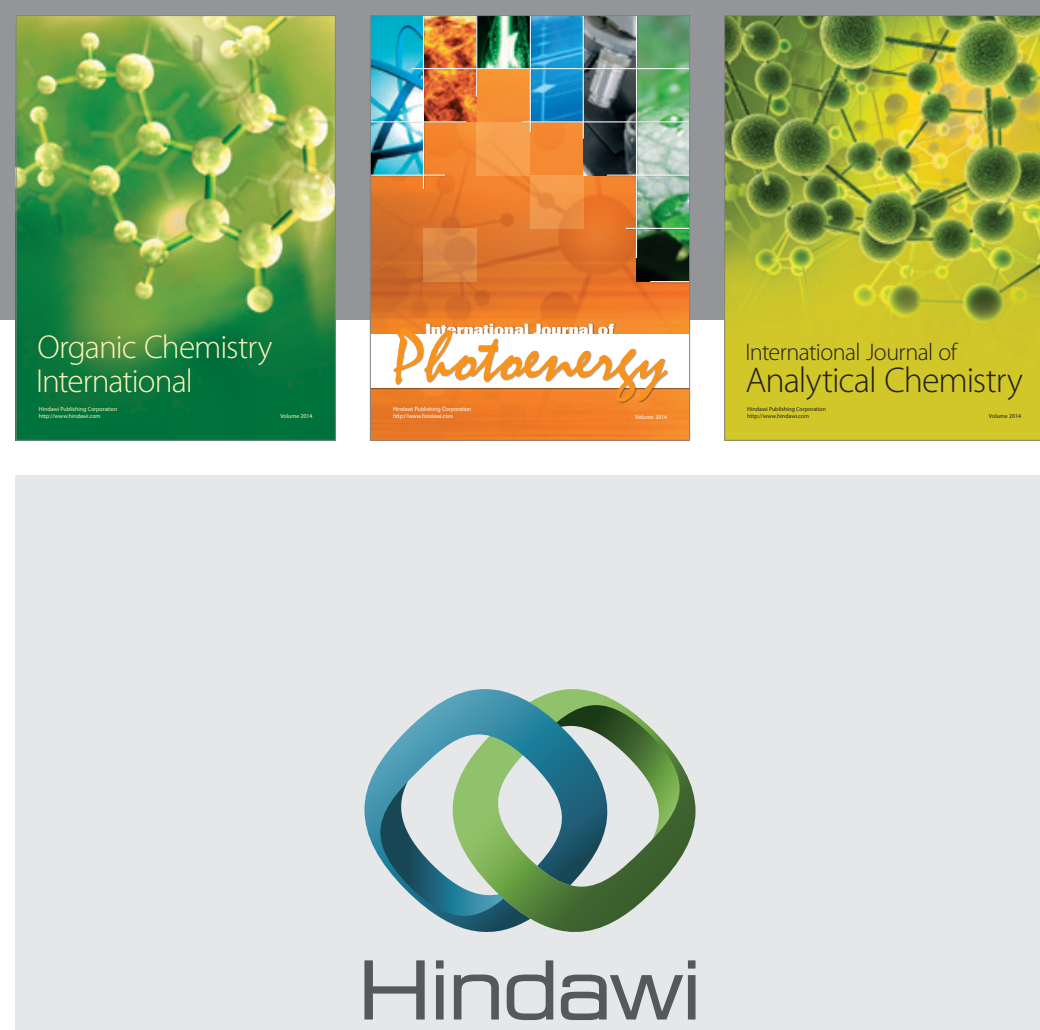

Submit your manuscripts at

http://www.hindawi.com
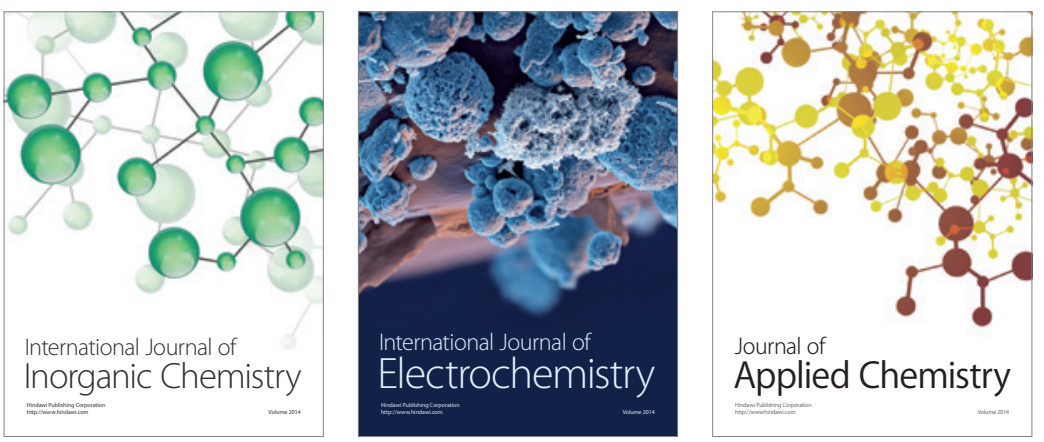

Journal of

Applied Chemistry
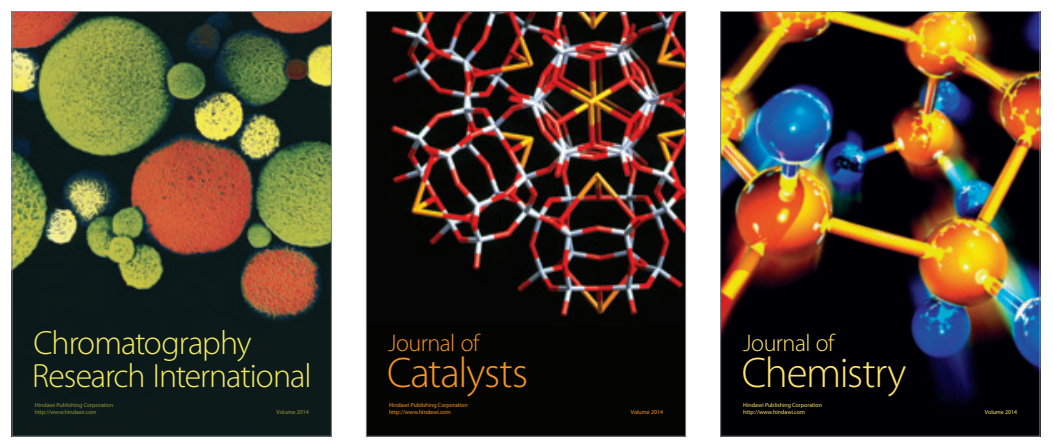
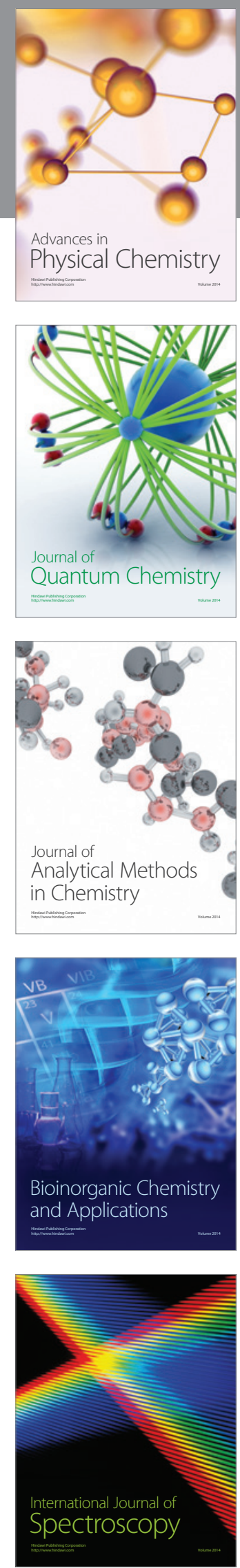